\title{
Immunological configuration of ovarian carcinoma: features and impact on disease outcome
}

\author{
Jitka Fucikova (D) , ${ }^{1,2}$ An Coosemans (D) , ${ }^{3}$ Sandra Orsulic, ${ }^{4}$ David Cibula (D) , ${ }^{5}$ \\ Ignace Vergote, ${ }^{6}$ Lorenzo Galluzzi, ${ }^{7,8,9}$ Radek Spisek ${ }^{1,2}$
}

To cite: Fucikova J, Coosemans A, Orsulic S, et al. Immunological configuration of ovarian carcinoma: features and impact on disease outcome. Journal for ImmunoTherapy of Cancer 2021;9:e002873. doi:10.1136/jitc-2021-002873

LG and RS are joint senior authors.

Accepted 09 September 2021

Check for updates

(C) Author(s) (or their employer(s)) 2021. Re-use permitted under CC BY-NC. No commercial re-use. See rights and permissions. Published by BMJ.

For numbered affiliations see end of article.

\section{Correspondence to}

Dr Jitka Fucikova;

fucikova@sotio.com

\begin{abstract}
Epithelial ovarian carcinoma (EOC) is a relatively rare malignancy but is the fifth-leading cause of cancer-related death in women, largely reflecting early, prediagnosis dissemination of malignant disease to the peritoneum. At odds with other neoplasms, EOC is virtually insensitive to immune checkpoint inhibitors, correlating with a tumor microenvironment that exhibits poor infiltration by immune cells and active immunosuppression. Here, we comparatively summarize the humoral and cellular features of primary and metastatic EOC, comparatively analyze their impact on disease outcome, and propose measures to alter them in support of treatment sensitivity and superior patient survival.
\end{abstract}

\section{INTRODUCTION}

Epithelial ovarian carcinoma (EOC) is among the top five causes of cancer-related death in women. ${ }^{1}$ Indeed, while EOC is relatively rare (it accounts for approximately $2 \%$ of all malignancies affecting women, basal cell and squamous cell skin cancers excluded), prognosis is particularly poor as most cases are diagnosed as late-stage invasive disease. ${ }^{1}$ EOC is traditionally classified into five histological subtypes: high-grade serous ovarian carcinoma (HGSOC), low-grade serous ovarian carcinoma (LGSOC), mucinous ovarian carcinoma (MOC), endometrioid ovarian carcinoma (EnOC), and ovarian clear cell carcinoma (OCCC), each of which has different cellular origins and molecular profiles. ${ }^{2}$ The immune contexture and density of tumor-infiltrating $\mathrm{T}$ lymphocytes (TILs) vary considerably among different EOCs, being highest in HGSOCs, intermediate in EnOCs, and lowest in LGSOCs, MOCs, and OCCCs. ${ }^{3}$ Consistent with a role for TIL in EOC progression, a recent study on more than 5900 advanced EOC patients demonstrated a markedly higher risk of mortality for women with MOC and OCCC subtypes as compared with patients with HGSOC and EnOC. ${ }^{4}$ HGSOC, in which epithelial ovarian cells or secretory cells are present in the mucosa of fallopian tubes, is the most common and aggressive form of EOC. ${ }^{2}$ Poor outcomes in HGSOC are largely dictated by early dissemination to the peritoneal cavity, especially the omentum, resulting in the formation of metastatic lesions and malignant ascites that ultimately resist currently approved therapeutic strategies. ${ }^{2}$ A recent study harnessing single-cell RNAseq has provided an even more in-depth resolution of HGSOC, identifying multiple subtypes with differential disease outcome. ${ }^{56}$

The majority of women with EOC achieve indeed complete remission after primary or interval cytoreductive surgery combined with chemotherapy based on a platinum-taxane doublet. Homologous recombination (HR) defects imposed by germline or somatic BRCA1 DNA repair-associated (BRCA1) or $B R C A 2$ mutations are not only key determinants of platinum sensitivity in EOC patients but also provide a strong rationale for maintenance therapy based on poly(ADP-ribose) polymerase (PARP) inhibitors, which is generally associated with improved progression-free survival (PFS). ${ }^{7}$ Nonetheless, more than $50 \%$ of women affected by EOC ultimately experience recurrence with treatment-resistant disease and succumb within 5 years of diagnosis, calling for the urgent development of novel therapeutic approaches to this deadly malignancy.

Successful introduction of immune checkpoint inhibitors (ICIs) for the treatment of multiple tumor types has created enormous expectations around the possibility of harnessing the patient's own immune system against EOC. ${ }^{8}$ However, compared with other neoplasms, such as non-small cell lung carcinoma and melanoma, EOC is poorly sensitive to ICIs employed as standalone immunotherapeutic agents, ${ }^{9}$ most likely due to indolent anticancer immunity and robust immunosuppression at baseline. ${ }^{10}$ In this 
context, a strongly immunosuppressive tumor microenvironment (TME) may considerably contribute to disease progression and metastatic dissemination, calling for the implementation of combinatorial immunotherapeutic strategies beyond immune checkpoint inhibition. ${ }^{11}$ Indeed, additional mechanisms appear to be crucial for the generation of an immunosuppressive contexture in EOC, including increased levels of immunomodulatory cytokines, enzymes and metabolites including interleukin (IL)-6, IL-10, vascular endothelial growth factor A (VEGFA), macrophage migration inhibitory factor (MIF), indoleamine 2,3-dioxygenase 1 (IDO1), arginase 1 (ARG1), and lactate. ${ }^{12-15}$ These factors increase along with disease progression, paralleling the accumulation of immunosuppressive cell types such as $\mathrm{CD} 4^{+} \mathrm{CD} 25^{+-}$ forkhead box P3 $\left(\mathrm{FOXP3}^{+}\right)$regulatory $\mathrm{T}\left(\mathrm{T}_{\mathrm{REG}}\right)$ cells, tumor-associated macrophages (TAMs), tolerogenic dendritic cells (DCs), and myeloid-derived suppressor cells (MDSCs). ${ }^{16-19}$ Thus, multiple immunosuppressive factors quench anticancer immunity in the TME of EOCs, hence representing potential therapeutic targets for drug development.

Importantly, recent technological developments, including modern genomic, transcriptomic and phenotypic assays at single-cell resolution, have provided an in-depth characterization of the cellular and humoral immune contexture of EOC and its impact on disease outcomes. If validated by independent prospective clinical studies, these immunological biomarkers may not only assist in determining the response of patients with EOC to treatment but also enable the adoption of personalized treatment approaches with superior likelihood for success. Here, we present key immunological features of primary versus metastatic EOC and critically discuss their potential value as prognostic and predictive biomarkers.

\section{THE IMMUNE MICROENVIRONMENT IN OVARIAN CARCINOMA}

The immunological contexture of both primary and metastatic EOC lesions builds on a complex network of immune and non-immune cells that interact, both physically and via soluble mediators, with each other, with malignant cells and with the extracellular matrix (figure $1 .^{20-22}$ Importantly, while some immune cells, such as T lymphocytes, B cells and DCs, can be found within EOC cell nests, many cellular components of the immune system, such as MDSCs, natural killer (NK) cells, mast cells and neutrophils, are primarily localized at the invasive margin. ${ }^{21}$ Moreover, it became clear that the immunological configurations of primary and metastatic EOC differ considerably from each other, ${ }^{20}{ }^{23}$ as well as that the degree of primary and metastatic EOC infiltration by immune cells exhibit considerable heterogeneity across patients. ${ }^{24-26}$ In this setting, analytical approaches that go beyond the mere estimation of cellular density in diagnostic biopsies to include spatial localization and functional orientation of the immune compartment of metastatic EOC have identified components of the EOC immune contexture that are linked to improved disease outcome, as discussed here below. ${ }^{1027}$

\section{T lymphocytes}

An elevated number of $\mathrm{T}$ lymphocytes infiltrating the tumor core or stroma has been linked to favorable prognosis in a large panel of malignancies. ${ }^{10}{ }^{28}$ In line with this notion, a high density of $\mathrm{CD}^{+} \mathrm{T}$ cells in either primary or metastatic tumor biopsies has been attributed to independent prognostic value for improved PFS and overall survival (OS) in numerous cohorts of women with EOC (table 1). ${ }^{3}{ }^{21} 29-40$ Importantly, such a positive prognostic impact is primarily associated with the expression of $\mathrm{CD}^{+} \mathrm{T}$ cell memory markers, markers of $\mathrm{CD}^{+} \mathrm{T}_{\mathrm{H}} 1$ polarization, and TIL localization to EOC islets rather than stromal areas. ${ }^{29} 4142$ Moreover, although $\mathrm{CD}^{+} \mathrm{T}$ cell density appears to be increased in metastatic EOC samples compared with their primary counterparts, ${ }^{20} 23$ the abundance of $\mathrm{CD}^{+} \mathrm{T}$ cells in either compartment retains prognostic value..$^{29} 43$

A retrospective analysis of the immune landscape of more than 7000 EOC samples encompassing all major histological subtypes (HGSOC, LGSOC, MOC, EnOC, and OCCC) revealed that the strong positive prognostic impact of $\mathrm{CD}^{+}$TILs is limited to HGSOC, MOC, and EnOC, but not LGSOC and OCCC. ${ }^{44}$ Intriguingly, HGSOC generally harbors the most dense immune infiltrate as compared with other EOC subtypes. ${ }^{44}$ These findings have largely been recapitulated by independent investigators. ${ }^{41}$ Of note, abundant $\mathrm{CD} 8^{+} \mathrm{T}$ cell infiltration was linked to favorable disease outcome, regardless of residual disease, therapeutic strategy, or germline BRCA1 mutations. ${ }^{44}$ Similar results were obtained in a meta-analysis encompassing the results of 10 previously published studies, ultimately including a total of 1815 patients encompassing all EOC histologies. ${ }^{28}$

Although some studies have attributed a negative prognostic value to robust EOC infiltration by TILs expressing programmed cell death 1 (PDCD1, best known as PD-1) or cytotoxic T lymphocyte-associated protein 4 (CTLA4), potentially linked to PD-1- or CTLA-4-dependent T cell exhaustion, ${ }^{35}$ other studies have revealed a rather beneficial prognosis, possibly because an elevated number of PD- $1^{+}$cells correlates with abundant tumor infiltration by $\mathrm{T}$ cells altogether ${ }^{45}$ or because a subset of $\mathrm{CD} 8^{+} \mathrm{PD}-1^{+} \mathrm{T}$ cells expressing integrin subunit alpha E (ITGAE, best known as CD103) retain functional competence in the ovarian TME. ${ }^{33}$ In support of this possibility, a subset of $\mathrm{CD}^{+} \mathrm{CD} 103^{+} \mathrm{T}$ cells that was preferentially localized at epithelial tumor regions and expressed cytotoxic molecules has been significantly correlated with improved disease outcome in HGSOC patients. ${ }^{33} 4647$ Conversely, $\mathrm{CD}^{+}$cytotoxic $\mathrm{T}$ lymphocytes (CTLs) expressing the coinhibitory receptor hepatitis A virus cellular receptor 2 (best known as TIM-3) exhibit bona fide features of functional exhaustion, and their abundance has been associated with poor disease outcome, indicating that TIM-3 plays a prominent role in limiting immune responses 


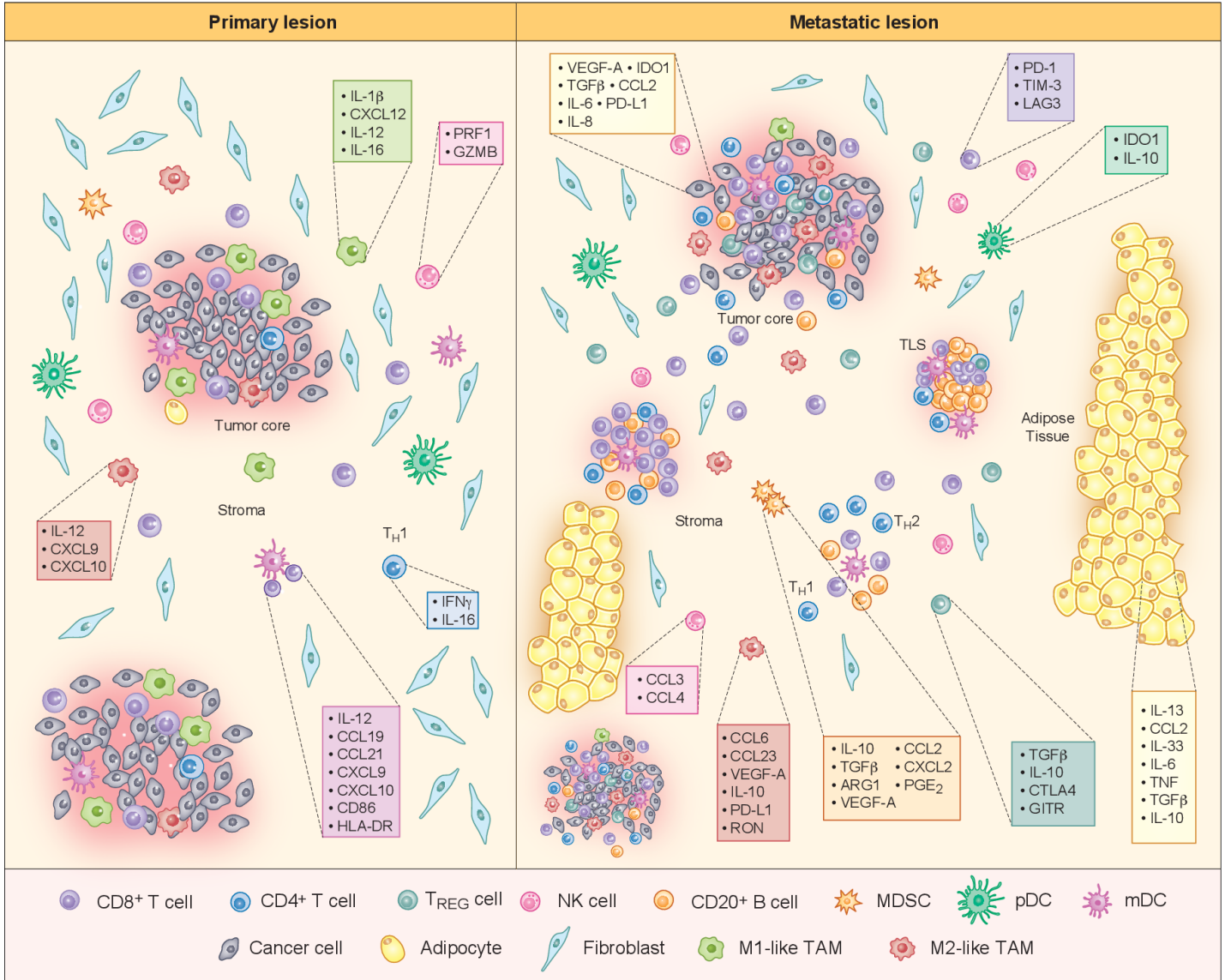

Figure 1 Principle of cancer immunosurveillance in primary and metastatic ovarian carcinoma. Primary immune cell populations, cytokines and chemokines involved in the interaction between primary and metastatic ovarian carcinoma and the host immune system. ARG1, arginase 1; CCL, chemokine (C-C motif) ligand; CXCL, chemokine (C-X-C motif) ligand; CTLA-4, cytotoxic T-lymphocyte-associated protein 4; GITR, glucocorticoid-induced TNFR related gene; GZMB, granzyme B; IDO1, indoleamine 2,3-dioxygenase 1; IFNG, interferon gamma; IL, interleukin; LAG3, lymphocyte activation gene 3; mDCs, myeloid dendritic cells; MDSCs, myeloid-derived suppressor cells; NK, natural killer; PD-1, programmed cell death 1; PD-L1, programmed death ligand 1; $\mathrm{pDC}$, plasmacytoid dendritic cell; $\mathrm{PGE}_{2}$, prostaglandin $\mathrm{E}_{2}$; PRF1, perforin 1; TAM, tumor-associated macrophage; TIM-3, coinhibitory receptor hepatitis A virus cellular receptor 2 (HAVCR2, best known as Tim-3); TGFB1, transforming growth factor beta 1; TLS, tertiary lymphoid structure; TNF, tumor necrosis factor; $\mathrm{T}_{\mathrm{REG}}$, regulatory T cell; VEGFA, vascular endothelial growth factor $A$.

against HGSOC (table 1). ${ }^{45}$ In line with this notion, recent studies have identified a key role for the coexpression of various coinhibitory receptors for T cell exhaustion/ dysfunction. ${ }^{48}$ Specifically, IL-27 was shown to drive a transcription program that promotes the coexpression of PD-1 and TIM-3, as well as lymphocyte activating 3 (LAG3) and $\mathrm{T}$ cell immunoreceptor with Ig and ITIM domains (TIGIT) ${ }^{48}$ Taken together, these findings identify a potential interaction between TIM-3 and other coinhibitory receptors that may be relevant for the establishment of robust immunosuppression in EOCs. In line with this possibility, coblockade of TIM-3 and PD-1 has been linked to tumor regression and improved anticancer $\mathrm{T}$ cell responses in patients with advanced solid carcinomas. ${ }^{50}$ Importantly, this combination might also circumvent some of the toxic effects observed with CTLA-4 and PD-1 coinhibition, as the expression of TIM-3 (but not CTLA-4 and PD-1) is predominantly linked to terminally differentiated T cells producing interferon gamma (IFNG).$^{50}$
In summary, tumor infiltration by $\mathrm{CD} 8^{+}$CTLs, memory $\mathrm{T}$ cells and $\mathrm{T}_{\mathrm{H}} 1$ cells is associated with prolonged PFS and OS, particularly in patients with HGSOC. Conversely, tumor infiltration by TIM- $3^{+}$cells stands out as a negative prognostic factor. The impact of $\mathrm{T}$ cells expressing other activation and exhaustion markers on EOC outcome remains to be precisely elucidated.

\section{$\mathrm{T}_{\text {REG }}$ cells}

$\mathrm{T}_{\mathrm{REG}}$ cells are a heterogeneous population of $\mathrm{CD}^{+} \mathrm{T}$ lymphocytes that express the high-affinity IL-2 receptor chain IL-2 receptor subunit alpha (best known as CD25) and the transcription factor FOXP3. ${ }^{51} \mathrm{~T}_{\mathrm{REG}}$ cells are essential for maintaining tolerance and preventing autoimmunity. ${ }^{51}$ However, developing malignancies, including EOC, harness $\mathrm{T}_{\mathrm{REG}}$ cells to establish local immunosuppression through a variety of mechanisms: (1) direct lysis of immune effector cells; (2) inhibition of antigen-presenting cells (APCs); (3) secretion of 
Table 1 Prognostic relevance of T lymphocytes, dendritic cells (DCs), tertiary lymphoid structures (TLSs) and B cells in primary and metastatic ovarian carcinoma

\begin{tabular}{|c|c|c|c|c|c|c|c|}
\hline & Histology & Stage & No of patients & Method & Impact & Note & Ref. \\
\hline \multicolumn{8}{|l|}{ T lymphocytes } \\
\hline \multicolumn{8}{|l|}{ Primary lesion } \\
\hline $\mathrm{CD}^{+} \mathrm{T}$ cell & HGSOC & All & 199 & $\mathrm{IHC}$ & Beneficial & $\begin{array}{l}\text { High density of } \mathrm{CD}^{+} \mathrm{T} \text { cells } \\
\text { correlated with improved disease } \\
\text { outcome }\end{array}$ & 3 \\
\hline \multirow{12}{*}{$\mathrm{CD8}^{+} \mathrm{T}$ cell } & $\mathrm{EOC}$ & All & 117 & $\mathrm{IHC}$ & Beneficial & $\begin{array}{l}\text { High density of } \mathrm{CD} 8^{+} \mathrm{T} \text { cells } \\
\text { correlated with favorable prognosis }\end{array}$ & 30 \\
\hline & EOC & All & 500 & $\mathrm{IHC}$ & Beneficial & $\begin{array}{l}\text { High density of } \mathrm{CD} 8^{+} \mathrm{T} \text { cells } \\
\text { associated with low } B R C A 1 \\
\text { expression }\end{array}$ & 41 \\
\hline & EOC & All & 497 & $\mathrm{IHC}, \mathrm{IF}$ & Beneficial & $\begin{array}{l}\text { High density of } \mathrm{CD} 103^{+} \mathrm{CD} 8^{+} \mathrm{T} \text { cells } \\
\text { correlated with improved survival }\end{array}$ & 33 \\
\hline & EOC & II, III, IV & 203 & IHC, RT-PCR & Beneficial & $\begin{array}{l}\text { High density of } \mathrm{CD} 8^{+} \mathrm{T} \text { cells } \\
\text { correlated with favorable disease } \\
\text { outcome }\end{array}$ & 34 \\
\hline & $\mathrm{EOC}$ & All & 70 & $\mathrm{IHC}$ & Beneficial & $\begin{array}{l}\mathrm{CD} 8^{+} \mathrm{T} \text { cells negatively correlated } \\
\text { with } \mathrm{PD}-\mathrm{L} 1 \text { expression in tumor }\end{array}$ & 35 \\
\hline & EOC & All & 199 & $\mathrm{IHC}$ & Beneficial & $\begin{array}{l}\text { High density of } \mathrm{CD} 8^{+} \mathrm{T} \text { cells } \\
\text { correlated with improved disease } \\
\text { outcome }\end{array}$ & 3 \\
\hline & $\begin{array}{l}\text { HGSOC, } \\
\text { EnOC, } \\
\text { OCCC }\end{array}$ & All & 135 & $\mathrm{IHC}$ & Beneficial & $\begin{array}{l}\text { High density of } \mathrm{CD} 103^{+} \mathrm{CD} 8^{+} \mathrm{T} \text { cells } \\
\text { correlated with improved disease } \\
\text { outcome }\end{array}$ & 22 \\
\hline & HGSOC & All & 178 & $\mathrm{IHC}$ & Beneficial & $\begin{array}{l}\text { CD8 }{ }^{+} T \text { cells were shown to abolish } \\
\text { clinically relevant chemoresistance } \\
\text { by altering glutathione and cystine } \\
\text { metabolism in malignant cells }\end{array}$ & 32 \\
\hline & HGSOC & All & 147 & $\mathrm{IHC}$ & Beneficial & $\begin{array}{l}\text { High density of } \mathrm{CD} 8^{+} \mathrm{T} \text { cells } \\
\text { correlated with improved disease } \\
\text { outcome }\end{array}$ & 21 \\
\hline & HGSOC & All & 232 & $\mathrm{IHC}$ & Beneficial & $\begin{array}{l}\text { High density of } \mathrm{CD}^{+} \mathrm{T} \text { cells } \\
\text { correlated with improved disease } \\
\text { outcome }\end{array}$ & 38 \\
\hline & HGSOC & All & 283 & $\mathrm{IHC}$ & Beneficial & $\begin{array}{l}\text { High density of } \mathrm{CD} 8^{+} \mathrm{T} \text { cells } \\
\text { correlated with favorable prognosis }\end{array}$ & 39 \\
\hline & HGSOC & All & 80 & IF & Detrimental & $\begin{array}{l}\text { High density of PD }-1^{+} \mathrm{TIM}-3^{+} \mathrm{CD} 8^{+} \\
\mathrm{T} \text { cells correlated with poor disease } \\
\text { outcome }\end{array}$ & 45 \\
\hline \multirow[t]{2}{*}{$\mathrm{CD}^{2} 5 \mathrm{RO}^{+} \mathrm{T}$ cell } & $\mathrm{EOC}$ & All & 270 & $\mathrm{IHC}$ & Beneficial & $\begin{array}{l}\text { High density of } \mathrm{CD} 45 \mathrm{RO}^{+} \text {memory } \\
\mathrm{T} \text { cells correlated with increased } \\
\text { disease specific survival }\end{array}$ & 29 \\
\hline & $\mathrm{EOC}$ & All & 33 & $\mathrm{IHC}$ & Beneficial & $\begin{array}{l}\text { High density of } \mathrm{CD} 45 \mathrm{RO}^{+} \mathrm{T} \text { cells } \\
\text { correlated with higher survival rate }\end{array}$ & 42 \\
\hline
\end{tabular}


Table 1 Continued

\begin{tabular}{|c|c|c|c|c|c|c|c|}
\hline & Histology & Stage & No of patients & Method & Impact & Note & Ref. \\
\hline \multirow[t]{10}{*}{$\mathrm{T}_{\mathrm{REG}}$ cell } & $\mathrm{EOC}$ & All & 270 & $\mathrm{IHC}$ & Beneficial & $\begin{array}{l}\text { High density of } T_{\text {REG }} \text { cells correlated } \\
\text { with favorable disease outcome }\end{array}$ & 29 \\
\hline & EOC & All & 92 & $\mathrm{IHC}, \mathrm{FC}$ & Detrimental & $\begin{array}{l}\text { High density of CD } 8^{+} T_{\text {REG }} \text { cells, } \\
\text { induced by TGFB1, correlated with } \\
\text { poor disease outcome }\end{array}$ & 66 \\
\hline & EOC & All & 232 & $\mathrm{IHC}$ & Detrimental & $\begin{array}{l}\text { High density of } T_{\text {REG }} \text { cells associated } \\
\text { with advanced stage of disease and } \\
\text { suboptimal debulking }\end{array}$ & 38 \\
\hline & EOC & III,IV & 26 & $\mathrm{IHC}, \mathrm{FC}$ & Detrimental & $\begin{array}{l}\text { High density of ICOS }{ }^{+} \mathrm{T}_{\mathrm{REG}} \text { cells, } \\
\text { dependent on ICOS-L stimulation by } \\
\mathrm{pDC} \text {, correlated with poor disease } \\
\text { outcome }\end{array}$ & 17 \\
\hline & $\mathrm{EOC}$ & All & 103 & $\mathrm{IF}$ & Detrimental & $\begin{array}{l}\text { High density of } \mathrm{T}_{\mathrm{REG}} \text { cells, inducing } \\
\text { the expression of } \mathrm{B} 7-\mathrm{H} 4 \text { on TAMs, } \\
\text { correlated with poor disease outcome }\end{array}$ & 56 \\
\hline & EOC & All & 869 & Meta-analyses & Detrimental & $\begin{array}{l}\text { High density of } T_{\text {REG }} \text { cells correlated } \\
\text { with poor disease outcome }\end{array}$ & 55 \\
\hline & EOC & All & 210 & $\mathrm{IHC}$ & Detrimental & $\begin{array}{l}\text { High density of } T_{R E G} \text { cells in lymphoid } \\
\text { aggregates correlated with reduced } \\
\text { survival time }\end{array}$ & 37 \\
\hline & HGSOC & All & 199 & $\mathrm{IHC}$ & Beneficial & $\begin{array}{l}\text { High density of } \mathrm{T}_{\mathrm{REG}} \text { cells correlated } \\
\text { with improved disease outcome }\end{array}$ & 3 \\
\hline & $\begin{array}{l}\text { HGSOC, } \\
\text { MOC, } \\
\text { Other }\end{array}$ & All & 99 & IHC, RT-PCR & Detrimental & $\begin{array}{l}\text { High density of } T_{\text {REG }} \text { cells correlated } \\
\text { with poor OS and PFS }\end{array}$ & 53 \\
\hline & $\begin{array}{l}\text { HGSOC, } \\
\text { MOC, } \\
\text { OCCC }\end{array}$ & All & 25 & FC,RNAseq, Cytof & Detrimental & $\begin{array}{l}\text { High density of } T_{\text {REG }} \text { cells, suppressing } \\
\mathrm{CD}^{+} \mathrm{T} \text { cells proliferation, correlated } \\
\text { with poor disease outcome }\end{array}$ & 62 \\
\hline $\mathrm{T}_{\mathrm{REG}} / \mathrm{T}_{\mathrm{H}} 17$ & EOC & III, IV & 124 & $\mathrm{IF}$ & Detrimental & $\begin{array}{l}\text { High } T_{\text {REG }} \text { cells } / T_{H} 17^{+} \text {cells ratio, } \\
\text { derived by TAMs, associated with } \\
\text { disease progression and metastasis }\end{array}$ & 60 \\
\hline \multicolumn{8}{|c|}{ Metastatic lesion } \\
\hline \multirow[t]{2}{*}{$\mathrm{CD8}^{+} \mathrm{T}$ cell } & $\mathrm{EOC}$ & III, IV & 147 & $\mathrm{IHC}$ & Beneficial & $\begin{array}{l}\text { High density of CD8 }{ }^{+} \text {CTLs in omental } \\
\text { metastasis correlated with improved } \\
\text { disease specific survival }\end{array}$ & 29 \\
\hline & HGSOC & III, IV & 80 & $\mathrm{IHC}$ & None & $\begin{array}{l}\text { High density of } \mathrm{CD}^{+} \mathrm{T} \text { cells in } \\
\text { peritoneal metastasis were not shown } \\
\text { to associate with disease outcome }\end{array}$ & 20 \\
\hline \multirow[t]{2}{*}{$\mathrm{CD} 4 \mathrm{RO}^{+}$cell } & EOC & III, IV & 147 & $\mathrm{IHC}$ & Beneficial & $\begin{array}{l}\text { High density of CD } 45 \mathrm{RO}^{+} \mathrm{T} \text { cells in } \\
\text { omental metastasis correlated with } \\
\text { improved disease specific survival }\end{array}$ & 29 \\
\hline & HGSOC & III, IV & 77 & $\mathrm{FC}$ & Beneficial & $\begin{array}{l}\text { High density of CD45RA }{ }^{-} C \mathrm{CR} 7^{-} \mathrm{CD}^{+} \\
\mathrm{T} \text { cells in peritoneal ascites correlated } \\
\text { with improved RFS }\end{array}$ & 43 \\
\hline$T_{\mathrm{REG}}$ cell & $\mathrm{EOC}$ & III, IV & 147 & $\mathrm{IHC}$ & Detrimental & $\begin{array}{l}\text { High density of } T_{\mathrm{REG}} \text { cells in omental } \\
\text { ascites, mediated by CCL22 } \\
\text { produced by cancer cells and TAMs, } \\
\text { correlated with poor disease outcome }\end{array}$ & 29 \\
\hline
\end{tabular}


Table 1 Continued

\begin{tabular}{|c|c|c|c|c|c|c|c|}
\hline & Histology & Stage & No of patients & Method & Impact & Note & Ref. \\
\hline $\mathrm{CD} 8 / \mathrm{T}_{\mathrm{REG}}$ & EOC & III, IV & 147 & $\mathrm{IHC}$ & Detrimental & $\begin{array}{l}\text { High CD8 }{ }^{+} T \text { cells } / T_{\text {REG }} \text { cells ratio in } \\
\text { omental metastasis correlated with } \\
\text { poor disease specific survival }\end{array}$ & 29 \\
\hline
\end{tabular}

\begin{tabular}{|c|c|c|c|c|c|c|c|}
\hline \multicolumn{8}{|l|}{ DCs } \\
\hline \multicolumn{8}{|c|}{ Primary lesion } \\
\hline \multirow[t]{4}{*}{$\mathrm{mDC}$} & ${ }^{*} \mathrm{EOC}$ & All & 33 & $\mathrm{IHC}$ & Beneficial & $\begin{array}{l}\text { High density of CD1 } \mathrm{a}^{+} \text {DCs correlated } \\
\text { with improved OS }\end{array}$ & 42 \\
\hline & n.a. & n.a. & n.a. & $\mathrm{FC}, \mathrm{IHC}$ & Benefical & $\begin{array}{l}\text { High level of CXCL17 correlated with } \\
\text { increased density of B7- } 4^{+} \text {DCs and } \\
\text { favorable disease outcome }\end{array}$ & 74 \\
\hline & n.a. & n.a. & n.a. & $\mathrm{FC}, \mathrm{IHC}$ & Beneficial & $\begin{array}{l}\text { High density of CD } 103^{+} \text {DCs, as } \\
\text { potent stimulators of CTLs, correlated } \\
\text { with favorable disease outcome }\end{array}$ & 72 \\
\hline & HGSOC & All & 147 & $\mathrm{IHC}$ & Benefical & $\begin{array}{l}\text { High density of mature DC-LAMP } \\
\text { DCs correlated with increased } \\
\text { frequency of CTLs and improved } \\
\text { disease outcome }\end{array}$ & 21 \\
\hline \multirow[t]{4}{*}{ pDC } & n.a. & All & 44 & $\mathrm{FC}$ & Detrimental & $\begin{array}{l}\text { High density of } \mathrm{CD} 4^{+} \mathrm{CD} 123^{+} \mathrm{BDCA} 2^{+} \\
\text {pDC correlated with poor disease } \\
\text { outcome }\end{array}$ & 77 \\
\hline & EOC & All & 60 & $\mathrm{IHC}, \mathrm{FC}$ & Detrimental & $\begin{array}{l}\text { High expression of IDO correlated } \\
\text { with reduced density of CD8 }{ }^{+} \mathrm{T} \text { cells, } \\
\text { tumor progression and poor disease } \\
\text { outcome }\end{array}$ & 78 \\
\hline & n.a. & n.a. & n.a. & $\mathrm{IHC}, \mathrm{FC}$ & Detrimental & $\begin{array}{l}\text { SDF-1 was shown to induce } \\
\text { chemotaxis and protection of pDCs } \\
\text { from TAM-mediated apoptosis }\end{array}$ & 79 \\
\hline & EOC & III, IV & 26 & $\mathrm{IHC}, \mathrm{FC}$ & Detrimental & $\begin{array}{l}\text { High density of HLA-DR }{ }^{+} \mathrm{CD}_{123^{+}} \mathrm{pDC} \\
\text { mediated stimulation of ICOS }{ }^{+} \mathrm{T}_{\mathrm{REG}} \\
\text { cells associated with poor disease } \\
\text { outcome }\end{array}$ & 17 \\
\hline \multicolumn{8}{|c|}{ Metastatic lesion } \\
\hline $\mathrm{mDC}$ & HGSOC & III, IV & 80 & $\mathrm{IHC}$ & Beneficial & $\begin{array}{l}\text { High density of mature DC-LAMP } \\
\text { DCs in peritoneal metastasis } \\
\text { correlated with improved disease } \\
\text { outcome }\end{array}$ & 20 \\
\hline pDC & n.a. & All & 44 & $\mathrm{FC}$ & Detrimental & $\begin{array}{l}\text { High density of } \mathrm{CD} 4^{+} \mathrm{CD} 123^{+} \mathrm{BDCA} 2^{+} \\
\text {pDCs in malignant ascites correlated } \\
\text { with poor disease outcome }\end{array}$ & 77 \\
\hline \multicolumn{8}{|c|}{ TLSs and B cells } \\
\hline \multicolumn{8}{|c|}{ Primary lesion } \\
\hline \multirow[t]{7}{*}{ B cell } & ${ }^{\star} \mathrm{EOC}$ & All & 135 & $\mathrm{IHC}$ & Beneficial & $\begin{array}{l}\text { High density of CD20+ } \mathrm{B} \text { cells } \\
\text { correlated with improved disease } \\
\text { outcome }\end{array}$ & 36 \\
\hline & EOC & All & 266 & RNAseq & Beneficial & $\begin{array}{l}\text { High BCR segments correlated with } \\
\text { improved prognosis }\end{array}$ & 82 \\
\hline & EOC & All & 154 & $\mathrm{IHC}$ & Detrimental & $\begin{array}{l}\text { High density of CD } 138^{+} \text {plasma cells } \\
\text { correlated with poor disease outcome }\end{array}$ & 85 \\
\hline & $\begin{array}{l}\text { HGSOC, } \\
\text { EnOC }\end{array}$ & All & 224 & RNAseq & Beneficial & $\begin{array}{l}\text { High expression of CD38 correlated } \\
\text { with favorable prognosis }\end{array}$ & 84 \\
\hline & HGSOC & All & 194 & $\mathrm{IHC}$ & Beneficial & $\begin{array}{l}\text { High density of CD } 27^{-} \mathrm{CD} 20^{+} \text {memory } \\
\mathrm{B} \text { cells correlated with cytolytic } \\
\text { immune response and favorable } \\
\text { prognosis }\end{array}$ & 81 \\
\hline & HGSOC & All & 147 & $\mathrm{IHC}$ & Beneficial & $\begin{array}{l}\text { High density of CD20 } 0^{+} \text {B cells } \\
\text { correlated with CTLs response and } \\
\text { improved RFS and OS }\end{array}$ & 21 \\
\hline & HGSOC & All & 199 & $\mathrm{IHC}$ & Beneficial & $\begin{array}{l}\text { High density of } \mathrm{CD}^{2} \mathrm{O}^{+} \mathrm{B} \text { cells } \\
\text { correlated with favorable disease } \\
\text { outcome }\end{array}$ & 3 \\
\hline
\end{tabular}


Table 1 Continued

\begin{tabular}{|c|c|c|c|c|c|c|c|}
\hline & Histology & Stage & No of patients & Method & Impact & Note & Ref. \\
\hline & HGSOC & All & 155 & $\mathrm{IHC}$ & Beneficial & $\begin{array}{l}\text { High density of CD20- } \\
\text { CD } 38^{+} \mathrm{CD} 138^{+} \mathrm{CD} 79 \mathrm{a}^{+} \text {plasma cells } \\
\text { correlated with CTLs response and } \\
\text { improved disease outcome }\end{array}$ & 83 \\
\hline \multirow[t]{2}{*}{ TLS } & HGSOC & All & 147 & $\mathrm{IHC}$ & None & $\begin{array}{l}\text { The presence of TLSs was not } \\
\text { associated with disease outcome }\end{array}$ & 21 \\
\hline & HGSOC & All & 155 & $\mathrm{IHC}$ & Beneficial & $\begin{array}{l}\text { TLSs were shown to facilitate the } \\
\text { development of antitumor immunity } \\
\text { associated with favorable disease } \\
\text { outcome }\end{array}$ & 83 \\
\hline \multicolumn{8}{|c|}{ Metastatic lesion } \\
\hline B cell & HGSOC & III, IV & 80 & $\mathrm{IHC}$ & None & $\begin{array}{l}\text { High density of CD20+ B cells in } \\
\text { peritoneal metastasis was not } \\
\text { associated with disease outcome }\end{array}$ & 20 \\
\hline
\end{tabular}

*Encompassing all EOC histological subtypes.

CTL, cytotoxic T lymphocyte; CXCL9, C-X-C motif chemokine ligand 9; EnOC, endometroid ovarian cancer; EOC, epithelial ovarian carcinoma; FC, flow cytometry; HGSOC, high-grade serous ovarian carcinoma; ICOS, inducible T cell costimulator; IDO, indoleamine 2,3-dioxygenase; IF, immunofluorescence; IHC, immunohistochemistry; LAMP, lysosomal-associated membrane protein; mDC, myeloid DC; MOC, mucinous ovarian cancer; n.a., not available; OCCC, clear cell ovarian cancer; OS, overall survival; PD-1, programmed cell death 1; pDC, plasmacytoid DC; PFS, progression-free survival; RFS, relapse-free survival; RNAseq, RNA-sequencing; TAM, tumor-associated macrophage; TGFB1, transforming growth factor beta 1; TIL, tumor-infiltrating lymphocyte; $\mathrm{T}_{\mathrm{REG}}$, regulatory $\mathrm{T}_{\text {cell. }}$

immunosuppressive cytokines, such as IL-10 and transforming growth factor beta 1 (TGFB1); and (4) depletion of growth factors and nutrients. ${ }^{52}$ While most circulating $\mathrm{T}_{\mathrm{REG}}$ cells stably express FOXP3 as a gene imprinted during thymic development, a tumor-infiltrating subset of $\mathrm{T}_{\mathrm{REG}}$ cells appears to retain some degree of plasticity and transdifferentiate towards a phenotype with limited immunosuppressive functions and the capacity to secrete IFNG and IL-17 under inflammatory conditions. ${ }^{51} 52$ Similarly, a subset of tumor-infiltrating $\mathrm{T}_{\mathrm{H}} 1$-polarized $\mathrm{CD}^{+}$ $\mathrm{T}$ cells can transdifferentiate into $\mathrm{FOXP}^{+} \mathrm{T}_{\mathrm{REG}}$ cells in response to TGFB1. ${ }^{51}$

The majority of studies have shown that a high prevalence of $\mathrm{T}_{\mathrm{REG}}$ cells within TILs is associated with poor outcome in patients with all EOC histologies, especially when overall CTL infiltration is limited (table 1). 17303738 53-56 Similar results were obtained by a meta-analysis of 869 patients encompassing all EOC histologies from four previous studies. ${ }^{55}$ Conversely, a positive prognostic value has been attributed to tumor-infiltrating $\mathrm{T}_{\mathrm{REG}}$ cells in a cohort of 270 HGSOC patients, most likely reflecting abundant TIL infiltration altogether. ${ }^{29}$ These findings suggest that the ratio of CTLs and $T_{\text {REG }}$ cells may constitute a superior indicator of active immunity in the ovarian TME, as validated in a number of studies. ${ }^{29} 3057$

Tumor-infiltration by $T_{\text {REG }}$ cells is influenced by a variety of mechanisms, including multiple pathways driven by TAMs. ${ }^{58}$ For instance, C-C motif chemokine ligand 22 (CCL22), produced by malignant cells and TAMs, recruits $\mathrm{T}_{\mathrm{REG}}$ cells through a $\mathrm{C}-\mathrm{C}$ motif chemokine receptor 4 (CCR4)-dependent mechanism. ${ }^{59}$ Moreover, miRNAs contained in TAM-derived exosomes appear to promote the interaction of $\mathrm{T}_{\mathrm{REG}}$ cells with CTLs, resulting in an increased $\mathrm{T}_{\mathrm{REG}} / \mathrm{T}_{\mathrm{H}} 17$ cell ratio and disease progression. ${ }^{60}$ Conversely, $\mathrm{T}_{\mathrm{REG}}$ cells promote expression of the immunosuppressive molecule V-set domain containing $\mathrm{T}$ cell activation inhibitor 1 (VTCN1, best known as B7-H4) on various APCs, including TAMs. ${ }^{56}$ Of note, hypoxia-induced upregulation of CCL28 also promotes the recruitment of $\mathrm{T}_{\mathrm{REG}}$ cells to the ovarian TME through a mechanism that involves CCR10 and ultimately leads to IL-10 production in support of disease progression. ${ }^{61}$ $\mathrm{T}_{\mathrm{REG}}$ cells isolated from HGSOCs express various receptors associated with TCR engagement, including the coinhibitory receptor PD-1 and the coactivating receptors inducible $\mathrm{T}$ cell costimulator and tumor necrosis factor (TNF) receptor superfamily member 9 (TNFRSF9, best known as $4-1 \mathrm{BB}) .{ }^{62}$ Moreover, compared with $\mathrm{T}_{\mathrm{REG}}$ cells from other carcinomas, $\mathrm{T}_{\mathrm{REG}}$ cells from EOCs exhibit a highly activated state and increased immunosuppressive capacity, as documented in numerous studies on various histological subtypes of EOC. ${ }^{62}$

Thus, the abundance of $\mathrm{T}_{\mathrm{REG}}$ cells in primary EOC is commonly associated with poor disease outcome and metastatic progression. Conversely, the impact of $\mathrm{T}_{\mathrm{REG}}$ cell infiltration in metastatic EOCs remains relatively unknown.

\section{Dendritic cells}

Conventional DCs (cDCs) are commonly viewed as superior APCs, largely reflecting their capacity to efficiently process extracellular antigens and present them on MHC-II and MHC-I molecules to naïve $\mathrm{CD} 4^{+}$and $\mathrm{CD}^{+}$ $\mathrm{T}$ cells, respectively, in the context of the abundant secretion of pro-inflammatory cytokines. ${ }^{63}$ Based on functional and phenotypic features, cDCs can be subdivided into at 
least two main subsets: type I (cDC1s) and type II cDCs (cDC2s) ${ }^{64}$ classified as CD11 c ${ }^{\text {low } H L A-D R ~}{ }^{+}$DEC205 ${ }^{+}$XCR $1^{+}$, and $\mathrm{CD} 11 \mathrm{c}^{+} \mathrm{HLA}-\mathrm{DR}^{+} \mathrm{CD} 11 \mathrm{~b}^{+} \mathrm{CD} 1 \mathrm{a}^{+} \mathrm{CD} 14^{+}$, respectively. ${ }^{63} \mathrm{cDC} 1 \mathrm{~s}$ are not only highly proficient at crosspriming tumor-targeting $\mathrm{CD}^{+}$CTLs in tumor draining lymph nodes but can also recruit $\mathrm{T}$ cells to the TME and provide them with proinflammatory cytokines ${ }^{64}$ Unfortunately, cDC1s are very rare in the ovarian TME and exhibit features of immaturity, especially at early disease stages, implying that they might contribute to tumor progression. ${ }^{64}$ At least in part, this reflects the abundance of immunosuppressive cytokines, including IL-10, TGFB1, and VEGFA, ${ }^{146566}$ and other immunosuppressive factors, including the PD-1 ligand CD274 (best known as PD-L1). ${ }^{67} 68$ In line with this notion, PD-L1 blockade enhances DC-mediated T-cell activation, correlating with IL-10 downregulation and increased secretion of IL-2 and IFNG. ${ }^{69}$

HGSOC infiltration by BAFT3-dependent $\mathrm{CD} 103^{+}$ cDC1s correlates with the abundance of C-X-C motif chemokine receptor 3 (CXCR3) ligands, including C-X-C motif chemokine ligand 9 (CXCL9), CXCL10, and CXCL11, which facilitate the recruitment of clinically relevant effector T cells into the TME. ${ }^{43}{ }^{70} \mathrm{CD} 103^{+} \mathrm{cDC} 1 \mathrm{~s}$ are also dependent on the transcription factor IFN regulatory factor 8 (IRF8) and zinc finger and BTB domain containing $4,{ }^{71}$ as well as the cytokines colony stimulating factor 2 (CSF2, best known as GM-CSF) and FMS-related receptor tyrosine kinase 3 ligand, which are associated with favorable clinical outcome in ovarian carcinoma. ${ }^{72} \mathrm{Simi}$ larly, the abundance of mature DCs expressing lysosomalassociated membrane protein 3 (LAMP3, best known as DC-LAMP) has been associated with improved prognosis in patients with various malignancies, including primary and metastatic HGSOC. ${ }^{21}$ Of note, the majority of mature DC-LAMP ${ }^{+}$DCs are localized to the tumor stroma and are associated with tertiary lymphoid structures (TLSs) rather than in direct contact with malignant cell nests. ${ }^{21} 73$ Nonetheless, an elevated density of mature DCs in the ovarian microenvironment correlates with biomarkers of $\mathrm{T}_{\mathrm{H}} 1$ polarization and cytotoxic activity, both of which are favorable indicators in patients with all EOC histologies (table 1)..$^{20214274}$

At odds with cDCs, plasmacytoid DCs (pDCs), defined as $\mathrm{CD} 11 \mathrm{c}^{-} \mathrm{CD} 123^{+} \mathrm{CD} 303^{+} \mathrm{HLA}-\mathrm{DR}^{\text {low }}$ cells, are mostly involved in antiviral immune responses, reflecting their capacity to produce elevated amounts of type I IFN on activation. ${ }^{75}$ High levels of pDCs in the ovarian microenvironment are generally associated with immunosuppression and poor prognosis, as comprehensively documented in patients with various EOC histological subtypes (table 1). ${ }^{17} 18$ 76-79 IL-10 and CXCL12 are the primary factors responsible for EOC infiltration by CXCR4-expressing pDC precursors, culminating in the accumulation of pDCs expressing the immunosuppressive enzyme IDO $1{ }^{7879}$ Consistent with this, a high density of pDCs in the EOC environment is associated with impaired TIL proliferation, decreased effector functions as well as neoangiogenesis and metastatic disease dissemination in preclinical disease models. ${ }^{15}$ Interestingly, tumorinfiltrating $\mathrm{CD}^{+} \mathrm{CD} 123^{+} \mathrm{BDCA}^{+}$pDCs exhibit a partially mature phenotype (indicative of activation) compared with their ascitesborne and bloodborne counterparts. ${ }^{77}$ However, these tumor-associated pDCs produce limited amounts of type I IFN, IL-6, CCL4, CCL5, and TNF on Toll-like receptor (TLR) stimulation, suggesting that local pDC dysfunction may contribute to disease progression. ${ }^{77}$

Altogether, these findings suggest that EOCs harness various mechanisms to alter DC functions to establish immunosuppressive circuitries that foster disease progression across various EOC subtypes. ${ }^{63} 76$ Thus, therapeutic interventions that restore DC functions stand out as promising approaches to initiate EOC-targeting immune responses of clinical relevance. ${ }^{80}$

\section{$B$ cells and TLSs}

Tumor infiltration by B cells is robustly associated with improved survival in patients with EOC, especially HGSOC (table 1). ${ }^{3} 2136$ 81-85 Nevertheless, accumulating findings suggest a positive impact of $\mathrm{B}$ cells also in other histological EOC subtypes, including MOC, EnOC, and OCCC. ${ }^{364}$ Although B cells primarily reside in the tumor stroma in the context of TLSs, they can also be found within tumor cell nests. ${ }^{86} \mathrm{~B}$ cells at all stages of differentiation have been detected in EOC, including $\operatorname{IgD}^{+} \mathrm{CD} 38^{+/-}$ naïve $\mathrm{B}$ cells, $\mathrm{IgD}^{+} \mathrm{CD} 38^{+}$pregerminal and $\mathrm{IgD}^{-} \mathrm{CD} 38^{+}$ germinal $\mathrm{B}$ cells; $\mathrm{IgD}^{-} \mathrm{CD} 38^{+/-}$memory $\mathrm{B}$ cells as well as plasma cells (PCs) with a $\operatorname{IgD}^{-} \mathrm{CD} 38^{++}$phenotype. $^{87}$ Similar to lymph nodes, TLSs contain prominent B-cell follicles adjoined by discrete T-cell zones containing $\mathrm{CD} 4^{+}$ and $\mathrm{CD}^{+} \mathrm{T}$ cells, as well as follicular DCs, high endothelial venules, and lymphatic vessels. ${ }^{73}$ TLSs are documented in only approximately $30 \%$ of all EOC patients, but their presence is strongly associated with favorable clinical outcome (table 1)..$^{21} 83$

Interestingly, in the ovarian setting, TLSs are frequently surrounded by dense infiltrates of mature PCs. ${ }^{83} 85$ PCs are generally associated with a high density of $\mathrm{CD} 8^{+}$and $\mathrm{CD} 4^{+} \mathrm{T}$ cells, as well as $\mathrm{CD} 20^{+} \mathrm{B}$ cells, which stands out as an immunological configuration compatible with the induction of clinically relevant tumor-targeting immunity. ${ }^{83} \mathrm{CD} 20^{+} \mathrm{B}$ cells are found in more than $40 \%$ of HGSOCs, and their abundance also correlates with tumor infiltration by $\mathrm{CD} 4^{+}$and $\mathrm{CD} 8^{+} \mathrm{T}$ cells, as well as with the abundance of transcripts encoding various $\mathrm{T}$ cell markers, such as TIA1 cytotoxic granule associated RNA binding protein (TIA1), granzyme B (GZMB) and FOXP3 $3{ }^{321}$ Importantly, abundant EOC infiltration by both $\mathrm{CD}^{+}$CTLs and $\mathrm{CD} 20^{+} \mathrm{B}$ cells is associated with a more favorable disease outcome than infiltration by either cell population alone, suggesting the existence of cooperative interactions between $\mathrm{CD} 8^{+} \mathrm{CTLs}$ and $\mathrm{CD} 20^{+} \mathrm{B}$ cells in the ovarian microenvironment. ${ }^{218183} \mathrm{In}$ line with this notion, the majority of EOC-infiltrating $\mathrm{CD} 20^{+} \mathrm{B}$ cells express high levels of costimulatory molecules, including CD80 and CD86, as well as MHC Class I and Class II molecules, 
as they display a $\mathrm{CD} 27^{-}$memory phenotype linked to markers of somatic hypermutation, oligoclonality and IgG class switching. ${ }^{88}$

As recently shown by us and others, both omental and peritoneal HGSOC metastases are highly infiltrated by $\mathrm{CD} 20^{+} \mathrm{B}$ cells with a memory phenotype. ${ }^{202389}$ As in primary EOCs, transcript levels of $\mathrm{CD} 20$ correlate with markers of cytotoxic responses, suggesting that B cells infiltrating metastatic EOC promote anticancer immune responses, a notion that has been mechanistically validated on B-cell depletion in syngeneic mouse models of peritoneal metastasis. ${ }^{89}$ Although the density of CD20 ${ }^{+}$ B cells is significantly increased in peritoneal metastases compared with primary EOC lesions, ${ }^{23}$ the abundance of metastasis-infiltrating $\mathrm{CD} 20^{+} \mathrm{B}$ cells is not associated with disease outcome (table 1). ${ }^{20}$

Taken together, these observations suggest that TLSs represent key sites for the induction and maintenance of clinically relevant EOC-targeting immunity and that B cells mediate a central function in this context. An improved understanding of the biology of tumor-infiltrating B cells is highly anticipated to harness this lymphocyte subset for therapeutic purposes.

\section{Tumor-associated macrophages}

TAMs, which constitute the largest fraction of the myeloid infiltrate in the majority of solid malignancies, including all EOCs, ${ }^{90}$ can be found within tumor cell nests, at the tumor invasive margin and in the stroma. A high degree of TAM heterogeneity has been observed not only across different histological subtypes of EOC, with HGSOCs and MOCs being the EOCs most abundantly infiltrated by TAMs, but also in women with the same EOC subtype and even different EOC lesions in the same patient. ${ }^{9091}$ Moreover, TAMs display a high degree of functional plasticity and can rapidly adapt to changing microenvironmental conditions to acquire different phenotypic, metabolic, and functional profiles. ${ }^{92}$ In particular, exposure of tumor-infiltrating monocytes and macrophages to cytokines, such as IL-4, IL-5, IL-10, IL-13, CCL2, TGFB1, and CSF1 (best known as M-CSF), as well as to prostaglandin $\mathrm{E}_{2}\left(\mathrm{PGE}_{2}\right)$, which is abundantly produced by dying cancer cells, promotes the acquisition of anti-inflammatory and protumoral (so-called M2-like) properties. ${ }^{93}$

In ovarian carcinoma, M2-like TAMs robustly promote neo-angiogenesis and disease progression in the context of largely immunosuppressive rewiring of the TME. ${ }^{94}$ In line with this notion, high levels of $\mathrm{CD} 206^{+} \mathrm{CD} 163^{+} \mathrm{CD} 204^{+}$ M2-like TAMs within primary and metastatic EOCs of all histologies are generally associated with reduced sensitivity to treatment and poor prognosis (table 2). ${ }^{65}$ 94-100 Conversely, M1-like TAMs, defined as $\mathrm{CD} 68^{+} \mathrm{CD} 86^{+} \mathrm{HLA}-$ $\mathrm{DR}^{+} \mathrm{iNOS}^{+}$cells, constitute a good prognostic factor in women with EOC, largely reflecting their ability to promote robust inflammatory responses that limit disease progression, although their presence is significantly decreased in the TME of patients with advanced EOC (table 2). ${ }^{91} 98101102$
The immunosuppressive functions of M2-like TAMs involve a variety of global anti-inflammatory cytokines (eg, IL-10 and TGFB1) and chemokines (eg, CCL17, CCL18, CCL22) that facilitate the following functions: (1) inhibiting antigen presentation to $\mathrm{T}$ cells, (2) subverting $\mathrm{DC}$ maturation, (3) blocking CTL effector functions, and (4) driving the recruitment of $\mathrm{T}_{\mathrm{REG}}$ cells. ${ }^{103}$ M2-like TAMs in the ovarian TME also limit immune effector functions by producing exosomes. ${ }^{60}$ Specifically, TAM-derived exosomes contain high amounts of proteins, as well as DNA, mRNA and miRNA molecules, which together suppress $\mathrm{T}$ cell activity and promote an imbalance between $\mathrm{T}_{\mathrm{REG}}$ cells and $\mathrm{T}_{\mathrm{H}} 17$ cells by directly targeting signal transducer and activator of transcription 3 (STAT3) in $\mathrm{CD} 4^{+}$T cells. ${ }^{60}$

Multiple studies have identified a crucial role for TAMs, especially CD $163^{+}$TIM- $4^{+}$omental TAMs, in the metastatic dissemination of ovarian cancer cells to the peritoneal cavity. ${ }^{19}$ Indeed, the specific depletion of this TAM population prevents the development of metastatic disease in mouse models of ovarian cancer, and the molecular circuitries that underlie these functions may represent a novel therapeutic target in the ovarian setting. ${ }^{19}$ Moreover, TAMs are important for the formation of spheroids during transcoelomic EOC metastasis. In particular, TAMs can produce large amounts of epidermal growth factor (EGF) to activate EGF receptor (EGFR) and VEGFC signaling in surrounding cells, ultimately leading to upregulation of multiple integrins and intercellular adhesion molecule 1 (ICAM1) and hence promoting cancer cell proliferation, migration, adhesion, spheroid formation and implantation into the peritoneal cavity. ${ }^{94}$ In line with this notion, EGFRblocking and ICAM1-blocking strategies inhibit spheroid formation and metastatic disease progression in mouse models of EOC, ${ }^{94}$ standing out as potential targets for the development of novel approaches to the management of EOC patients.

Finally, TAMs support tumor progression by increasing the availability of selected nutrients in the primary, and even more so metastatic, ovarian TME. Specific TAM subsets can indeed accumulate lipids in support of their immunomodulatory properties, ultimately leading to deregulation of multiple factors involved in lipid metabolism, including the lipid chaperones fatty acid binding protein 4 (FABP4) and FABP5. ${ }^{104}$ In advanced EOC, TAMs preferentially express FABP4, which supports tumor progression by favoring IL-6-driven STAT3 signaling. ${ }^{105}$ FABP4 also plays a key role in the interaction between ovarian cancer cells and adipocytes. ${ }^{104}$ In line with these observations, FABP4 deficiency impairs metastatic tumor growth in mouse models of EOC. ${ }^{106}$ Intriguingly, EOC cells actively promote cholesterol efflux by TAMs, culminating in depletion of lipid rafts and increased IL-4 signaling. ${ }^{107}$ Thus, genetic deletion of the $\mathrm{ABC}$ transporters that mediate cholesterol efflux limits EOC progression in mice. ${ }^{107}$

Altogether, these findings indicate that EOCs harness macrophage polarization to an M2-like phenotype as a mean to establish immunosuppression in support of local and distant disease dissemination. The therapeutic 
Table 2 Prognostic relevance of tumor-associated macrophages (TAMs), myeloid-derived suppressor cells (MDSCs), natural killer (NK) cells and cancer associated fibroblasts (CAFs) in primary and metastatic ovarian carcinoma

\begin{tabular}{|c|c|c|c|c|c|c|c|}
\hline & Histology & Stage & Noofpatients & Method & Impact & Note & Ref. \\
\hline \multicolumn{8}{|l|}{ TAMs } \\
\hline \multicolumn{8}{|c|}{ Primary lesion } \\
\hline \multirow{2}{*}{ M1-like TAM } & EOC & III, IV & 102 & $\mathrm{IHC}, \mathrm{IF}$ & Beneficial & $\begin{array}{l}\text { High M1/M2-like TAMs ratio } \\
\text { correlated with improved } \\
\text { disease outcome }\end{array}$ & 98 \\
\hline & EOC & All & 112 & $\mathrm{IHC}, \mathrm{IF}$ & Beneficial & $\begin{array}{l}\text { High M1/M2-like TAMs ratio } \\
\text { correlated with improved } \\
\text { disease outcome }\end{array}$ & 101 \\
\hline \multirow[t]{5}{*}{ M2-like TAM } & EOC & All & 794 & Meta-analyses & Detrimental & $\begin{array}{l}\text { High density of M2-like TAMs } \\
\text { correlated with poor disease } \\
\text { outcome }\end{array}$ & 95 \\
\hline & EOC & III, IV & 102 & $\mathrm{IHC}, \mathrm{IF}$ & Detrimental & $\begin{array}{l}\text { High expression of Mucin-2 } \\
\text { correlated with low M1/ } \\
\text { M2-like TAMs ratio and poor } \\
\text { disease outcome }\end{array}$ & 98 \\
\hline & EOC & III & 128 & $\mathrm{IHC}$ & Detrimental & $\begin{array}{l}\text { High density of EGF-secreting } \\
\text { M2-like TAMs correlated with } \\
\text { poor disease outcome }\end{array}$ & 94 \\
\hline & EOC & All & 124 & IHC, IF & Detrimental & $\begin{array}{l}\text { High density of TAMs-derived } \\
\text { exosomes correlated with } \\
\text { high } T_{R E G} / T_{H} 17 \text { ratio and poor } \\
\text { disease outcome }\end{array}$ & 60 \\
\hline & HGSOC & All & 199 & IHC, IF & Detrimental & $\begin{array}{l}\text { High density of CD } 206^{+} \mathrm{CD} 68^{+} \\
\text {cells correlated with poor } \\
\text { disease outcome }\end{array}$ & 96 \\
\hline \multicolumn{8}{|c|}{ Metastatic lesion } \\
\hline M1-like TAM & EOC & III, IV & 140 & $\mathrm{FC}$ & Beneficial & $\begin{array}{l}\text { High density of M1-like TAMs } \\
\text { in malignant ascites correlated } \\
\text { with favorable disease } \\
\text { outcome }\end{array}$ & 102 \\
\hline \multirow[t]{3}{*}{ M2-like TAM } & EOC & III & 128 & $\mathrm{IHC}$ & Detrimental & $\begin{array}{l}\text { High density of EGF-secreting } \\
\text { M2-like TAMs correlated with } \\
\text { poor disease outcome }\end{array}$ & 65 \\
\hline & HGSOC & III, IV & 50 & IF & Detrimental & $\begin{array}{l}\text { High density of CD } 68^{+} \text {CD } 163^{+} \\
\text {M2-like TAMs in peritoneal } \\
\text { metastasis correlated with } \\
\text { poor RFS and OS }\end{array}$ & 20 \\
\hline & HGSOC & All & 30 & $\mathrm{FC}$ & Detrimental & $\begin{array}{l}\text { High density of M2-like TAMs } \\
\text { in malignant ascites correlated } \\
\text { with poor RFS and OS }\end{array}$ & 94 \\
\hline
\end{tabular}


Table 2 Continued

\begin{tabular}{|c|c|c|c|c|c|c|c|}
\hline & Histology & Stage & Noofpatients & Method & Impact & Note & Ref. \\
\hline \multicolumn{8}{|l|}{ MDSCs } \\
\hline \multicolumn{8}{|c|}{ Primary lesion } \\
\hline \multirow{6}{*}{ MDSC } & $\begin{array}{l}\text { HGSOC, } \\
\text { EnOC, } \\
\text { MOC }\end{array}$ & All & 29 & FC & None & $\begin{array}{l}\text { High density of PD-L1+ } \\
\text { MDSCs was not associated } \\
\text { with disease outcome }\end{array}$ & 117 \\
\hline & HGSOC & III, IV & 79 & $\mathrm{IF}, \mathrm{FC}$ & Detrimental & $\begin{array}{l}\text { High expression of } \\
\text { AMPK } \alpha 1 \text { associated with } \\
\text { immunosuppressive activity of } \\
\text { MDSCs }\end{array}$ & 124 \\
\hline & HGSOC & III, IV & 56 & Microarray IHC & Detrimental & $\begin{array}{l}\text { High VEGF levels correlated } \\
\text { with MDSC migration and } \\
\text { poor prognosis }\end{array}$ & 14 \\
\hline & n.a. & All & 60 & $\mathrm{IHC}$ & Detrimental & $\begin{array}{l}\text { High density of MDSCs } \\
\text { associated with stemness } \\
\text { of cancer cells induced by } \\
\text { CSF2/p-STAT3 signaling } \\
\text { pathway }\end{array}$ & 114 \\
\hline & n.a. & All & 340 & IHC, IF & Detrimental & $\begin{array}{l}\text { High levels of PGE2 produced } \\
\text { by MDSCs correlated with } \\
\text { increased PD-L1 expression } \\
\text { and stem cell-like properties } \\
\text { of cancer cells }\end{array}$ & 116 \\
\hline & n.a. & III, IV & n.a. & RT-PCR, ELISA & Detrimental & $\begin{array}{l}\text { High levels of CXCL1/2 } \\
\text { correlated with Snail } \\
\text { expression, MDSC infiltration } \\
\text { and poor disease outcome }\end{array}$ & 115 \\
\hline \multicolumn{8}{|c|}{ Metastatic lesion } \\
\hline \multirow[t]{4}{*}{ MDSC } & EOC & III, IV & n.a. & ELISA, FC & Detrimental & $\begin{array}{l}\text { High CXCL12 levels correlated } \\
\text { with accumulation of MDSCs } \\
\text { in malignant ascites and poor } \\
\text { disease outcome }\end{array}$ & 113 \\
\hline & EOC & All & 29 & $\mathrm{FC}$ & Detrimental & $\begin{array}{l}\text { High density of M-MDSCs in } \\
\text { peritoneal fluid correlated with } \\
\text { poor disease outcome }\end{array}$ & 110 \\
\hline & EOC & All & 31 & ELISA & Detrimental & $\begin{array}{l}\text { High IL- } 6 \text { and IL-10 levels } \\
\text { correlated with accumulation } \\
\text { of CD14 }{ }^{+} \text {HLA-DR }{ }^{-} \text {MDSCs in } \\
\text { malignant ascites and poor } \\
\text { disease outcome }\end{array}$ & 111 \\
\hline & EOC & III, IV & 13 & FC ELISA & Detrimental & $\begin{array}{l}\text { High density of MDSCs in } \\
\text { malignant ascites correlated } \\
\text { with increased level of } \mathrm{NO} \text { and } \\
\text { enhance development of } \mathrm{T}_{\mathrm{H}} 17 \\
\text { cells from CD4 }{ }^{+} \text {precurcors }\end{array}$ & 119 \\
\hline
\end{tabular}


Table 2 Continued

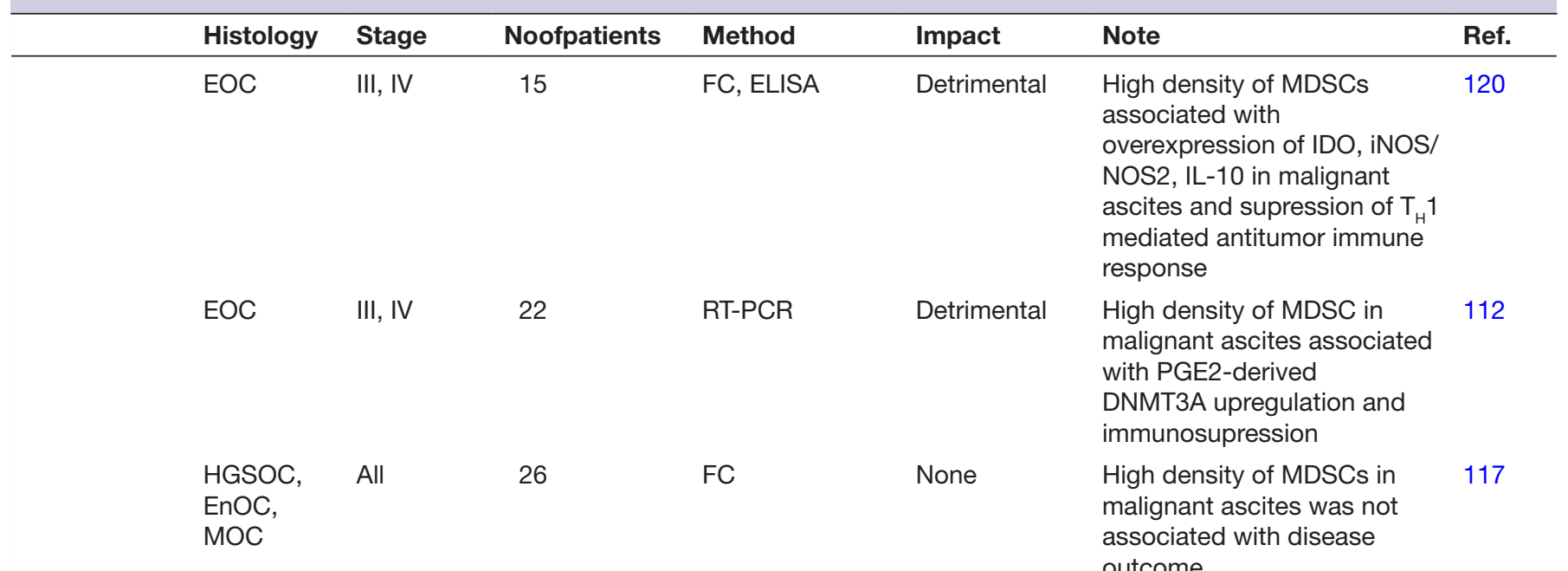

\begin{tabular}{|c|c|c|c|c|c|c|c|}
\hline \multicolumn{8}{|l|}{ NK cells } \\
\hline \multicolumn{8}{|c|}{ Primary lesion } \\
\hline \multirow[t]{3}{*}{ NK cells } & ${ }^{\star} \mathrm{EOC}$ & All & 497 & $\mathrm{IHC}, \mathrm{IF}$ & Beneficial & $\begin{array}{l}\text { High density of } \mathrm{CD} 103^{+} \mathrm{NK} \\
\text { cells correlated with favorable } \\
\text { disease outcome }\end{array}$ & 33 \\
\hline & HGSOC & All & 283 & $\mathrm{IHC}$ & Beneficial & $\begin{array}{l}\text { High density of } \mathrm{CD} 57^{+} \mathrm{NK} \\
\text { cells correlated with favorable } \\
\text { prognosis }\end{array}$ & 39 \\
\hline & $\begin{array}{l}\text { Serous, } \\
\text { MOC, } \\
\text { EnOC }\end{array}$ & All & 38 & $\mathrm{IHC}, \mathrm{IF}$ & Beneficial & $\begin{array}{l}\text { High expression of MIF } \\
\text { correlated with impaired NK } \\
\text { cells cytotoxicity and poor } \\
\text { prognosis }\end{array}$ & 13 \\
\hline \multirow{2}{*}{ NK cells } & HGSOC & III, IV & 20 & $\mathrm{FC}$ & Beneficial & $\begin{array}{l}\text { High density of CD56 }{ }^{+} \mathrm{NK} \\
\text { cells in peritoneal ascites } \\
\text { correlated with improved OS } \\
\text { and RFS }\end{array}$ & 127 \\
\hline & $\begin{array}{l}\text { Papillary } \\
\text { serous }\end{array}$ & III & 50 & $\mathrm{FC}$ & Detrimental & $\begin{array}{l}\text { Low expression of NKp30 } \\
\text { correlated with impaired } \\
\text { cytotoxicity and poor disease } \\
\text { outcome }\end{array}$ & 131 \\
\hline CAF & ${ }^{*} \mathrm{EOC}$ & All & 527 & $\mathrm{IHC}$ & Detrimental & $\begin{array}{l}\text { High levels of IL-1 } \beta \text { and low } \\
\text { expression of p53 in CAFs } \\
\text { correlated with poor disease } \\
\text { outcome }\end{array}$ & 142 \\
\hline
\end{tabular}


Table 2 Continued

\begin{tabular}{|c|c|c|c|c|c|c|c|}
\hline & Histology & Stage & Noofpatients & Method & Impact & Note & Ref. \\
\hline & EOC & II,III,IV & 255 & $\mathrm{IHC}$ & Detrimental & $\begin{array}{l}\text { High levels of IL- } 6 \text { in CAFs } \\
\text { correlated with paclitaxel } \\
\text { chemoresistance and poor } \\
\text { disease outcome }\end{array}$ & 224 \\
\hline & HGSOC & n.a. & n.a. & $\mathrm{IHC}$ & Detrimental & $\begin{array}{l}\text { High expression of } \\
\text { LPP correlate with } \\
\text { chemoresistance and poor } \\
\text { disease outcome }\end{array}$ & 149 \\
\hline & HGSOC & III, IV & 15 & Microarray & Detrimental & $\begin{array}{l}\text { High expression of versican } \\
\text { (VCAN) in CAFs mediated by } \\
\text { TGFB1 promote the motility } \\
\text { and invasion of tumor cells }\end{array}$ & 146 \\
\hline & HGSOC & III, IV & 144 & RT-PCR & Detrimental & $\begin{array}{l}\text { High levels of HOXA9 } \\
\text { stimulate CAFS and correlated } \\
\text { with poor disease outcome }\end{array}$ & 153 \\
\hline & n.a. & n.a. & n.a. & ELISA & Detrimental & $\begin{array}{l}\text { High expression of FGF1 } \\
\text { correlated with disease } \\
\text { progression and poor } \\
\text { outcome }\end{array}$ & 139 \\
\hline & n.a. & n.a. & n.a. & IF & Detrimental & $\begin{array}{l}\text { High levels of CAFs } \\
\text { associated with } \\
\text { chemoresistance and poor } \\
\text { disease outcome }\end{array}$ & 150 \\
\hline \multicolumn{8}{|c|}{ Metastatic lesion } \\
\hline \multirow[t]{2}{*}{ CAF } & HGSOC & III, IV & n.a. & $\begin{array}{l}\text { miRNA, } \\
\text { gene array } \\
\text { analyses }\end{array}$ & Detrimental & $\begin{array}{l}\text { MicroRNAs reprogram } \\
\text { normal fibroblasts into CAFs } \\
\text { associated with poor disease } \\
\text { outcome }\end{array}$ & 143 \\
\hline & HGSOC & III, IV & n.a. & ELISA & Detrimental & $\begin{array}{l}\text { High level of TGFB1 in CAF } \\
\text { exosomes correlated with } \\
\text { poor disease outcome }\end{array}$ & 154 \\
\hline
\end{tabular}

*Encompassing all EOC histological subtypes

CSF2, colony stimulating factor 2; CXCL12, C-X-C motif chemokine ligand 12; EGF, epidermal growth factor; EnOC, endometroid ovarian cancer; EOC, epithelial ovarian carcinoma; FAB, fatty acid binding; FC, flow cytometry; FGF1, fibroblast growth factor 1; HGSOC, high-grade serous ovarian carcinoma; iDC, immature dendritic cell; IDO1, indoleamine 2,3-dioxygenase; IF, immunofluorescence; IHC, immunohistochemistry; IL-6, interleukin; MIF, migration inhibitory factor; M-MDSC, monocytic MDSC; MOC, mucinous ovarian cancer; n.a., not available; NO, nitric oxide; OS, overall survival; PD-L1, programmed death ligand 1; PFS, progression-free survival; $\mathrm{PGE}_{2}$, prostaglandin E2; RFS, relapse-free survival; STAT3, signal transducer and activator of transcription 3; TGFB1, transforming growth factor beta $1 ; \mathrm{T}_{\mathrm{REG}}$, regulatory $\mathrm{T}$ cell; VEGF, vascular endothelial growth factor.

potential of TAM-targeting or TAM-repolarizing agents, such as CSF 1 receptor (CSF1R) inhibitors in patients with EOC, however, remains to be elucidated.

\section{Myeloid-derived suppressor cells}

MDSCs are a heterogeneous population of relatively immature myeloid cells that differ in morphology and function from terminally differentiated myeloid cells, such as DCs, macrophages and neutrophils. ${ }^{108}$ There are two major groups of MDSCs in humans, namely, granulocytic/polymorphonuclear MDSCs (PMN-MDSCs), which generally display a $\mathrm{CD} 11 \mathrm{~b}^{+} \mathrm{CD} 33^{+} \mathrm{CD} 14^{-} \mathrm{CD} 15^{+}$surface phenotype, and monocytic MDSCs (M-MDSCs), which are most often $\mathrm{CD} 11 \mathrm{~b}^{+} \mathrm{CD} 33^{+} \mathrm{CD} 14^{+} \mathrm{CD} 15^{-}$MDSCs. ${ }^{109}$

An increased number of circulating or tumor-infiltrating MDSCs has been detected in patients with various malignancies, ${ }^{109}$ including women with primary and metastatic 
EOC. ${ }^{16} 110111$ Nevertheless, association between histological subtypes of EOC and MDSC abundance has never been investigated. Various tumor-derived cytokines (eg, IL-6, IL-10, IL-18, TNF, and VEGFA), growth factors (eg, M-CSF, GM-CSF) and other mitogens (eg, PGE $_{2}$ ) promote the formation of MDSCs from myeloid progenitors in the bone marrow. ${ }^{1411-113}$ This largely reflects the activation of signaling transduction cascades culminating with STAT3 signaling, which also promotes MDSC immunosuppression by downregulating IRF8 while upregulating CCAAT enhancer binding protein beta. ${ }^{114}$ Conversely, the accumulation of MDSCs within neoplastic lesions is driven by a variety of cytokines and chemokines, including CXCL1, CXCL8, CXCL12, CCL1, CCL2, CCL3, CCL5 and CCL7, which primarily operate via CCR4 and CCR5. ${ }^{113} 115$

Accumulating preclinical and clinical evidence indicates that PMN-MDSCs and M-MDSCs suppress both innate and adaptive immune responses driven by ovarian cancer cells. ${ }^{1616-120}$ While the majority of such studies focused on HGSOCs, data from a limited number of patients with MOC and EnOC also support the protumoral role of MDCSs. ${ }^{110}$ Of note, PMN-MDSCs preferentially use reactive oxygen species, peroxynitrite, $\mathrm{ARG} 1$ and $\mathrm{PGE}_{2}$ to mediate immune suppression. ${ }^{112}{ }^{119}$ Conversely, M-MDSCs predominantly harness nitric oxide, immunosuppressive cytokine such as IL-10 and TGFB1, and membrane-bound molecules, such as PD-L1 to impair CTL and NK cell functions. ${ }^{121}$ MDSCs also drive tumor progression by favoring epithelial-to-mesenchymal transition (EMT), invasiveness and metastatic dissemination in malignant cells and by promoting neoangiogenesis. ${ }^{114} 116$ Recent data suggest that MDSCs are also involved in the establishment of the premetastatic niche. ${ }^{122}$ Consistent with these findings, elevated numbers of circulating or intratumoral MDSCs correlate with poor disease outcome in women with various EOC subtypes (table 2). ${ }^{14} 110112113123124$

Altogether, these observations suggest that both M-MDSCs and PMN-MDSCs establish immunosuppression and support metastatic dissemination in EOC. Thus, targeting MDSCs stands out as a promising approach to promote EOC-directed immune responses. Potential approaches to this objective include (1) blocking the formation of MDSCs in the bone marrow, (2) impeding MDSC recruitment to neoplastic lesions, and/or (3) reprogramming MDSCs to terminally differentiate and lose their immunosuppressive potential.

\section{NK cells}

NK cells are a subset of innate lymphoid cells that play a central role in defending the organism from viral infection, early malignant transformation and metastatic tumor dissemination. ${ }^{125}{ }^{126} \mathrm{NK}$ cell effector functions encompass potent cytotoxicity against target cells, as well as the secretion of immunomodulatory cytokines that orchestrate innate and adaptive immune responses. ${ }^{126}$ Such functions do not involve the recognition of specific antigens, as they do in the case of CTLs, but are controlled by the balance between inhibitory and stimulatory signals that are conveyed to NK cells on interaction with potential targets. ${ }^{125}$

Results on EOC infiltration by NK cells are rather inconsistent, at least in part due to the use of rather heterogeneous markers for NK cell detection (table 2). ${ }^{13} 20213339127128$ Thus, high levels of NK cells in the TME of all EOC subtypes have been positively associated with improved prognosis when beta-1,3glucuronyltransferase 1 (best known as CD57) and CD103 were used as phenotypic markers, although these molecules are also expressed by activated CD8 ${ }^{+}$ T cells. ${ }^{33}{ }^{39}$ In contrast, when NK cells were identified using natural cytotoxicity triggering receptor 1 (NCR1, best known as NKp46), their abundance in primary and metastatic HGSOC lesions did not correlate with clinical outcome, ${ }^{20}{ }^{21}$ perhaps due to functional impairments imposed by local immunosuppression. ${ }^{129}$ Indeed, NK cell effector functions in peritoneal ascites are inhibited on MIF-driven downregulation of killer cell lectin-like receptor K1 (KLRK1, best known as NKG2D) ${ }^{13}{ }^{130}$ Additionally, NK cell cytotoxicity in the TME of metastatic EOC is limited on the downregulation of NCR2 (best known as NKp30), as induced by soluble and surface-exposed NK cell cytotoxicity receptor 3 ligand 1 (NCR3LG1, best known as B7-H6). ${ }^{131}$ In line with these findings, increased B7-H6 expression has been associated with metastatic disease progression and poor clinical outcome in patients with various EOC histological subtypes. ${ }^{100}$

In addition to mediating direct cytotoxic effects against neoplastic cells, NK cells can also exert anticancer activity by engaging the adaptive arm of the immune system. Specifically, NK cells can recruit cDCs to the TME on secretion of CCL5, X-C motif chemokine ligand 1 (XCL1) and XCL2. ${ }^{132}$ Moreover, IL-18-primed NK cells can favor tumor infiltration through immature DCs via CCL3 and CCL4, a process that culminates in the secretion of CTL chemoattractants, including CXCR3 and CCR5 ligands. ${ }^{133}$

Altogether, these observations indicate that NK cells dynamically interact with malignant and immune components of the ovarian TME most often in support of anticancer immunity. However, available data fail to elucidate a robust prognostic value for EOC infiltration by NK cells, potentially linked to an elevated degree of methodological heterogeneity and/or to the functional impairment of EOC-infiltrating NK cells downstream of local immunosuppression. Efforts aimed at homogenizing the quantification of EOC-infiltrating NK cells and obtaining further insights into their functional rewiring on tumor infiltration are urgently needed to clarify the therapeutic potential of NK cell-targeting agents in women with EOC. ${ }^{126}$

\section{Cancer-associated fibroblasts}

Cancer-associated fibroblasts (CAFs) are key components of the ovarian TME with diverse biological functions, including matrix remodeling as well as reciprocal interactions with TILs and cancer cells. ${ }^{134} 135$ Tissue-resident quiescent fibroblasts, which are predominant in the normal stroma, and mesenchymal stem cells transform 
into CAFs on interaction with cancer cells. ${ }^{136} 137$ CAFs found in EOC lesions generally express actin alpha 1, skeletal muscle (ACTA1, best known as SMA), fibroblast activation protein alpha, S100 calcium binding protein A (S100A4, best known as FSP1) and fibroblast growth factor 1 (FGF1). ${ }^{138} 139$ However, due to the continuous reciprocal interactions between CAFs with cancer cells, the former tend to undergo dynamic changes that enable high degrees of phenotypical and functional heterogeneity. ${ }^{139}{ }^{140}$ Indeed, neoplastic cells secrete various cytokines and soluble factors such as IL-6, IL-8, IL-1 $\beta$, TGFB1, platelet-derived growth factor, FGF and EGF to activate fibroblasts. ${ }^{141} 142$ Moreover, ovarian cancer cells reprogram fibroblasts to become CAFs via alternations in the levels of 3 miRNAs, namely downregulation of miR-214 and miR-31, coupled to upregulation of miR-155. ${ }^{143}$

On reprogramming, CAFs promote tumor growth and invasion through increased secretion of multiple cytokines, chemokines and growth factors such as CCL5, IL-6, IL-8, TGFB1, VEGFA among others. ${ }^{144-146}$ Moreover, CAFs promote EOC progression by favoring the $\mathrm{EMT}^{141}$; angiogenesis, ${ }^{147}$; altered cancer metabolism ${ }^{144}{ }^{148}$; chemoresistance, ${ }^{32} 149150$ and immune modulation. ${ }^{151} 152$ However, an extensive description of all the mechanisms through which CAFs drive EOC progression goes largely beyond the scope to of this review, and can be found elsewhere. ${ }^{134} 135$ Importantly, CAF abundance positively correlate with disease progression and poor disease outcome in women with primary 138139142150153 and metastatic EOC $^{143144154}$ (table 2).

In summary, CAFs may also constitute valuable target to limit immunosuppression in the TME of patients with EOC. So far, this strategy has been mostly been investigated in other tumors with a large CAF component, such as pancreatic carcinoma. ${ }^{134}$

\section{Cytokine and chemokine profile}

Accumulating preclinical and clinical evidence indicates that the cytokine and chemokine milieu of EOC plays a key role in the establishment of local and systemic immune contexture (table 3)..$^{155} 156$ Thus, the intratumoral or circulating abundance of multiple cytokines and chemokines impacts disease outcome in patients with EOC. For instance, elevated IL-6 levels in the ovarian TME have been associated with disease progression, resistance to treatment and poor clinical outcome in patients with various EOC subtypes. ${ }^{156-159}$ At least in part, this reflects the ability of IL- 6 to promote EOC cell invasion through the basal membrane, as well as to (1) mediate mitogenic effects linked to chemoresistance and (2) promote IL-10 secretion. ${ }^{160}$ Moreover, IL-6 reportedly activates protumorigenic signal transducers, including JAK1 (Janus kinase 1) and STAT3. ${ }^{161}{ }^{162}$ In metastatic EOC, TAMs are the primary producers of IL-6, and their presence, as well as high bloodborne and peritoneal IL-6 levels, correlate with poor disease outcome. ${ }^{65} 111159160$ Similar findings have been obtained with IL-8, IL-10, VEGFA, TGFB1 and $\mathrm{TNF}$, all of which appear to condition the ovarian TME in favor of disease progression and escape from immunosurveillance (figure 2 and table 3). ${ }^{14} 6566156$ 163-168

The overall chemokine landscape of EOC is heterogeneous, with CCL2, CCL5, CXCL12 and CXCL16 being the most predominant molecules. ${ }^{155}$ Importantly, the high levels of CXCR6 and CXCL16 in serous papillary carcinoma tissues suggests an association with aggressive histological subtype as compared with EnOC. ${ }^{169}$ CCL2 is mostly produced by malignant cells and contributes to TAM accumulation. ${ }^{170}$ Conversely, while CCL4 and CCL5 expression is mostly associated with CTL recruitment, ${ }^{133}{ }^{171}$ CCL22 and CCL28 levels positively correlate with an increased abundance of $\mathrm{T}_{\mathrm{REG}}$ cells (at least in primary EOCs). ${ }^{54} 61155$ The expression of genes associated with $\mathrm{T}$ cell recruitment is restricted to the epithelial tumor component and preserved across metastatic sites, suggesting that $\mathrm{T}$ cells might easily home to metastatic lesions. ${ }^{155}$ However, the impact of some cytokines and chemokines on EOC progression and clinical outcome is controversial. For instance, although EOC-derived CXCL12 is associated with T cell recruitment, ${ }^{172}$ as are CXCL9 and CXCL10, ${ }^{70}$ it also drives tumor progression by activating the MAPK cascade in EOC cells, ${ }^{173}$ and promotes tumor infiltration by myeloid cells. ${ }^{113156}$ Consistent with this notion, high levels of CXCL12 or its receptor (CXCR3), as well as CXCL16, CXCR6 and CCL8, have been associated with metastatic dissemination to the peritoneum and ascites formation (table 3)..$^{169173-175}$

In summary, the net effect of cytokine and chemokine signaling on EOC progression depends on the balance between their ability to recruit and activate specific immune cell populations and their capacity to drive mitogenic signaling in EOC cells.

\section{MODULATING THE OVARIAN TME}

EOC was one of the first malignancies in which a positive association between TIL density and OS was identified. ${ }^{40}$ However, EOC-infiltrating lymphocytes are often suppressed and/or functionally exhausted by a variety of mechanisms, including (but not limited to) (1) abundant secretion of immunosuppressive cytokines, such as TGFB1, IL-6 and IL-10, by EOC cells ${ }^{6566156163}$; (2) expression of metabolic immunosuppressors, such as IDO $1^{78}$; (3) robust tumor infiltration by immunosuppressive $\mathrm{T}_{\mathrm{REG}}$ cells, ${ }^{38} 4654$ M2-like TAMs and MDSCs ${ }^{94}{ }^{95}$; and (4) activation of coinhibitory receptors, such as PD-1 and TIM- $3 .{ }^{45}{ }^{176}$ In line with such multipronged immunosuppression, ICIs are not very effective in women with EOC. ${ }^{177}$

\section{Chemotherapy}

Some anticancer agents, including conventional chemotherapeutics, targeted drugs and radiation therapy (RT), can be harnessed to stimulate anticancer immunity, as they can increase the antigenicity of malignant cells, boost their adjuvanticity or repolarize the TME in support of immunological disease control. ${ }^{178}$ At least in principle, 
Table 3 Pro-tumoral and anti-tumoral roles of cytokines and chemokines in primary and metastatic ovarian carcinoma

\begin{tabular}{|c|c|c|c|c|c|c|c|}
\hline & Histology & Stage & $\begin{array}{l}\text { No of } \\
\text { patients }\end{array}$ & Method & Impact & Note & Ref. \\
\hline \multicolumn{8}{|c|}{ Primary lesion } \\
\hline \multirow{2}{*}{ IL-6 } & EOC & All & 221 & $\mathrm{IHC}$ & Detrimental & $\begin{array}{l}\text { High IL-6 levels correlated } \\
\text { with tumor growth, high } \\
\text { frequency of TAMs infiltrate, } \\
\text { angiogenesis and poor } \\
\text { disease outcome }\end{array}$ & 157 \\
\hline & HGSOC & III, IV & 53 & IHC, IF & Detrimental & $\begin{array}{l}\text { High IL-6 levels correlated } \\
\text { with angiogenesis, increased } \\
\text { infiltration of myeloid cells } \\
\text { and poor disease outcome }\end{array}$ & 156 \\
\hline IL-10 & HGSOC & III, IV & 30 & ELISA & Detrimental & $\begin{array}{l}\text { High IL-10 levels correlated } \\
\text { with M2-like TAMs } \\
\text { polarization and poor } \\
\text { prognosis }\end{array}$ & 65 \\
\hline TGF $\beta$ & EOC & All & 92 & $\mathrm{IHC}, \mathrm{FC}$ & Detrimental & $\begin{array}{l}\text { High TGFB1 levels } \\
\text { associated with CD8 } \\
\text { Treg induction and poor } \\
\text { prognosis }\end{array}$ & 66 \\
\hline \multirow[t]{2}{*}{ TNF $\alpha$} & EOC & III, IV & 60 & $\begin{array}{l}\text { FC, ELISA, } \\
\text { RT-PCR }\end{array}$ & Detrimental & $\begin{array}{l}\text { High TNF levels correlated } \\
\text { with myeloid cells } \\
\text { recruitment and tumor } \\
\text { progression }\end{array}$ & 165 \\
\hline & HGSOC & III, IV & 53 & $\mathrm{IHC}, \mathrm{IF}$ & Detrimental & $\begin{array}{l}\text { High TNF levels correlated } \\
\text { with angiogenesis, increased } \\
\text { infiltration of myeloid cells } \\
\text { and poor disease outcome }\end{array}$ & 156 \\
\hline IDO & EOC & All & 60 & $\mathrm{IHC}$ & Detrimental & $\begin{array}{l}\text { High IDO levels correlated } \\
\text { with impaired OS and PFS }\end{array}$ & 78 \\
\hline CCL2 & $\begin{array}{l}\text { HGSOC, } \\
\text { MOC, } \\
\text { EnOC }\end{array}$ & All & 46 & ELISA & Detrimental & $\begin{array}{l}\text { High CCL2 levels correlated } \\
\text { with TAMs recruitment and } \\
\text { poor disease outcome }\end{array}$ & 170 \\
\hline CCL5 & n.a. & All & n.a. & $\begin{array}{l}\text { ELISA, } \\
\text { RT-PCR }\end{array}$ & Beneficial & $\begin{array}{l}\text { High CCL5 levels associated } \\
\text { with recruitment of effector } \\
\text { CD8 }{ }^{+} T \text { cells and favorable } \\
\text { disease outcome }\end{array}$ & 133 \\
\hline
\end{tabular}


Table 3 Continued

\begin{tabular}{|c|c|c|c|c|c|c|c|}
\hline & Histology & Stage & $\begin{array}{l}\text { No of } \\
\text { patients }\end{array}$ & Method & Impact & Note & Ref. \\
\hline CCL18 & HGSOC, MOC & All & 59 & $\begin{array}{l}\text { RT-PCR, } \\
\mathrm{IHC}\end{array}$ & Detrimental & $\begin{array}{l}\text { High CCL18 levels correlated } \\
\text { with metastatic spread and } \\
\text { poor disease outcome }\end{array}$ & 175 \\
\hline CCL22 & EOC & All & 70 & ELISA & Detrimental & $\begin{array}{l}\text { High CCL22 levels } \\
\text { associated with recruitment } \\
\text { of } T_{\text {REG }} \text { cells and poor } \\
\text { disease outcome }\end{array}$ & 54 \\
\hline CCL28 & HGSOC & III, IV & 88 & $\mathrm{IHC}$ & Detrimental & $\begin{array}{l}\text { High CCL28 levels } \\
\text { associated with recruitment } \\
\text { of } T_{\text {REG }} \text { cells and poor } \\
\text { disease outcome }\end{array}$ & 61 \\
\hline $\begin{array}{l}\text { CXCL9, } \\
\text { CXCL10 }\end{array}$ & HGSOC & III, IV & 184 & $\mathrm{IHC}$ & Beneficial & $\begin{array}{l}\text { High CXCL9 and CXCL10 } \\
\text { levels associated with } \\
\text { recruitment of effector } \\
\text { CD8 }{ }^{+} T \text { cells and favorable } \\
\text { prognosis }\end{array}$ & 70 \\
\hline \multirow[t]{2}{*}{ CXCL12 } & HGSOC & III, IV & 53 & IHC IF & Detrimental & $\begin{array}{l}\text { High CXCL12 levels } \\
\text { correlated with angiogenesis, } \\
\text { increased infiltration of } \\
\text { myeloid cells and poor } \\
\text { disease outcome }\end{array}$ & 156 \\
\hline & HGSOC, EnOC & All & 44 & $\mathrm{IHC}$ & Detrimental & $\begin{array}{l}\text { High CXCR } 4 \text { expression } \\
\text { correlated with cancer } \\
\text { cells proligeration and poor } \\
\text { disease outcome }\end{array}$ & 173 \\
\hline CXCL13 & HGSOC & All & 264 & $\mathrm{IHC}, \mathrm{IF}$ & Beneficial & $\begin{array}{l}\text { High CXCL13 levels } \\
\text { correlated with recruitment } \\
\text { of CXCR5 }{ }^{+} \mathrm{CD} 8^{+} \mathrm{T} \text { cells in } \\
\text { TLS and favorable disease } \\
\text { outcome }\end{array}$ & 190 \\
\hline \multicolumn{8}{|c|}{ Metastatic lesion } \\
\hline \multirow[t]{3}{*}{ IL-6 } & EOC & All & 70 & Luminex & Detrimental & $\begin{array}{l}\text { High IL-6 levels in malignant } \\
\text { ascites correlated with } \\
\text { chemo-resistance and poor } \\
\text { PFS }\end{array}$ & 168 \\
\hline & EOC & All & 31 & ELISA & Detrimental & $\begin{array}{l}\text { High IL- } 6 \text { and IL-10 levels } \\
\text { correlated with accumulation } \\
\text { of CD } 14^{+} H L A-D R^{-} \text {MDSCs in } \\
\text { malignant ascites and poor } \\
\text { disease outcome }\end{array}$ & 111 \\
\hline & HGSOC & III, IV & 30 & ELISA & Detrimental & $\begin{array}{l}\text { High IL- } 6 \text { levels correlated } \\
\text { with accumulation of } \\
\text { CD163 }{ }^{+} \text {CD } 68^{+} \text {M2-like TAMs } \\
\text { in malignant ascites and } \\
\text { poor disease outcome }\end{array}$ & 65 \\
\hline IL-10 & HGSOC & III, IV & 30 & ELISA & Detrimental & $\begin{array}{l}\text { High IL-10 levels correlated } \\
\text { with M2-like TAMs } \\
\text { polarization and poor } \\
\text { prognosis }\end{array}$ & 65 \\
\hline
\end{tabular}


Table 3 Continued

\begin{tabular}{|c|c|c|c|c|c|c|c|}
\hline & Histology & Stage & $\begin{array}{l}\text { No of } \\
\text { patients }\end{array}$ & Method & Impact & Note & Ref. \\
\hline VEGF & HGSOC & III, IV & 56 & Microarray IHC & Detrimental & $\begin{array}{l}\text { High VEGF levels correlated } \\
\text { with accumulation of MDSCs } \\
\text { and poor disease outcome }\end{array}$ & 14 \\
\hline TNF $\alpha$ & EOC & All & 70 & Luminex & Detrimental & $\begin{array}{l}\text { High TNF } \alpha \text { levels in } \\
\text { malignant ascites correlated } \\
\text { with chemoresistance and } \\
\text { poor PFS }\end{array}$ & 168 \\
\hline CCL18 & HGSOC & III, IV & 53 & $\begin{array}{l}\text { RT-PCR, } \\
\text { ELISA, WB }\end{array}$ & Detrimental & $\begin{array}{l}\text { High CCL18 levels correlated } \\
\text { with cancer cells proliferation } \\
\text { and metastatic spread }\end{array}$ & 174 \\
\hline CCL22 & n.a. & All & 70 & ELISA & Detrimental & $\begin{array}{l}\text { High CCL22 levels correlated } \\
\text { with recruitment of } T_{\text {REG }} \text { cells } \\
\text { and poor disease outcome }\end{array}$ & 54 \\
\hline
\end{tabular}

*Encompassing all EOC histological subtypes

CCL18, C-C motif chemokine ligand 18; CXCL12, C-X-C motif chemokine ligand 12; DC, dendritic cell; EnOC, endometroid ovarian cancer; EOC, epithelial ovarian carcinoma; FC, flow cytometry; HGSOC, high-grade serous ovarian carcinoma; IDO, indoleamine 2,3-dioxygenase; IF, immunofluorescence; IHC, immunohistochemistry; IL6, interleukin 6; MDSC, myeloid-derived suppressor cell; MOC, mucinous ovarian cancer; n.a., not available; OS, overall survival; PFS, progression-free survival; TAM, tumor associated macrophage; TGFB, transforming growth factor; TLS, tertiary lymphoid structure; TNF $\alpha$, tumor necrosis factor alpha; $T_{\text {REG }}$, regulatory T cell; VEGF, vascular endothelial growth factor; WB, western blotting.

genotoxic chemotherapies and RT can favor the formation and/or expression of mutated neoepitopes. ${ }^{179}$ However, expression levels may remain low and hence be incompatible with robust immune recognition. Chemotherapeutic agents used for the clinical management of platinum-resistant EOC, including doxorubicin, oxaliplatin and paclitaxel, are known to drive immunogenic cell death, ${ }^{180}$ which is associated with the abundant emission of immunostimulatory molecules commonly known as damage-associated molecular patterns (DAMPs) and thus might synergize with immunotherapy. ${ }^{178}{ }^{181}$ In line with this notion, pegylated doxorubicin has been shown to boost the uptake of dying EOC cells by cDCs and ultimately promote the cross-priming of $\mathrm{T}$ cells specific to EOC-associated antigens. ${ }^{182}$ However, the combination of pegylated doxorubicin with an ICI specific for PD-L1 (avelumab) failed to demonstrate superior activity compared with standard of care in a recent phase III clinical trial. ${ }^{183} 184$ Similar findings have been documented in a randomized phase II study testing the combination of pegylated doxorubicin with a TLR 8 (TLR8) agonist (motolimod). ${ }^{185}$ In addition to promoting polyploidization and hence boosting the immunogenicity of EOC cells, ${ }^{186}$ paclitaxel promotes the repolarization of M2-like TAMs into their M1-like counterparts, as well as the depletion of $\mathrm{T}_{\mathrm{REG}}$ cells and MDSCs from the ovarian TME. ${ }^{187}$ However, available preclinical data are insufficient to support the initiation of clinical trials testing paclitaxel in combination with ICIs in women with advanced EOC.
Metronomic cyclophosphamide has also been shown to deplete $\mathrm{T}_{\mathrm{REG}}$ cells from the ovarian TME, suggesting some potential for synergy with immunotherapeutic regimens. ${ }^{188}$ In line with this notion, metronomic cyclophosphamide combined with an angiogenesis inhibitor and a PD-1-targeting ICI (pembrolizumab) is well tolerated and mediates clinical benefits in $95.0 \%$ and durable treatment responses (>12 months) in $25.0 \%$ of women with recurrent EOC. ${ }^{189}$

\section{Immune checkpoint inhibitors.}

PD-1, CTLA-4, LAG3, TIM-3, and other coinhibitory receptors are widely expressed by EOC-infiltrating cells and mediate robust immunosuppressive effects. ${ }^{45} 176$ Thus, ICIs a priori represent a valid strategy to reverse local immunosuppression in women with EOC. However, comprehensive phenotypic and functional analyses of EOC-infiltrating $\mathrm{T}$ cells and the ovarian TME have revealed the existence of a multilayered immunosuppressive network, ${ }^{176}{ }^{190}$ potentially explaining the poor clinical activity of ICIs documented so far in patients with EOC. Indeed, in the first phase II study evaluating the efficacy of a PD-1-targeting ICI (nivolumab) for recurrent EOC, the overall response rate (ORR) in 20 assessable patients was only $15 \%$, with a $10 \%$ durable complete response rate. ${ }^{11}$ Similarly, the use of pembrolizumab as a single therapeutic agent for EOC has been linked to an ORR of $9 \%$, which was primarily associated with increased expression of PD-L1. ${ }^{191}$ 


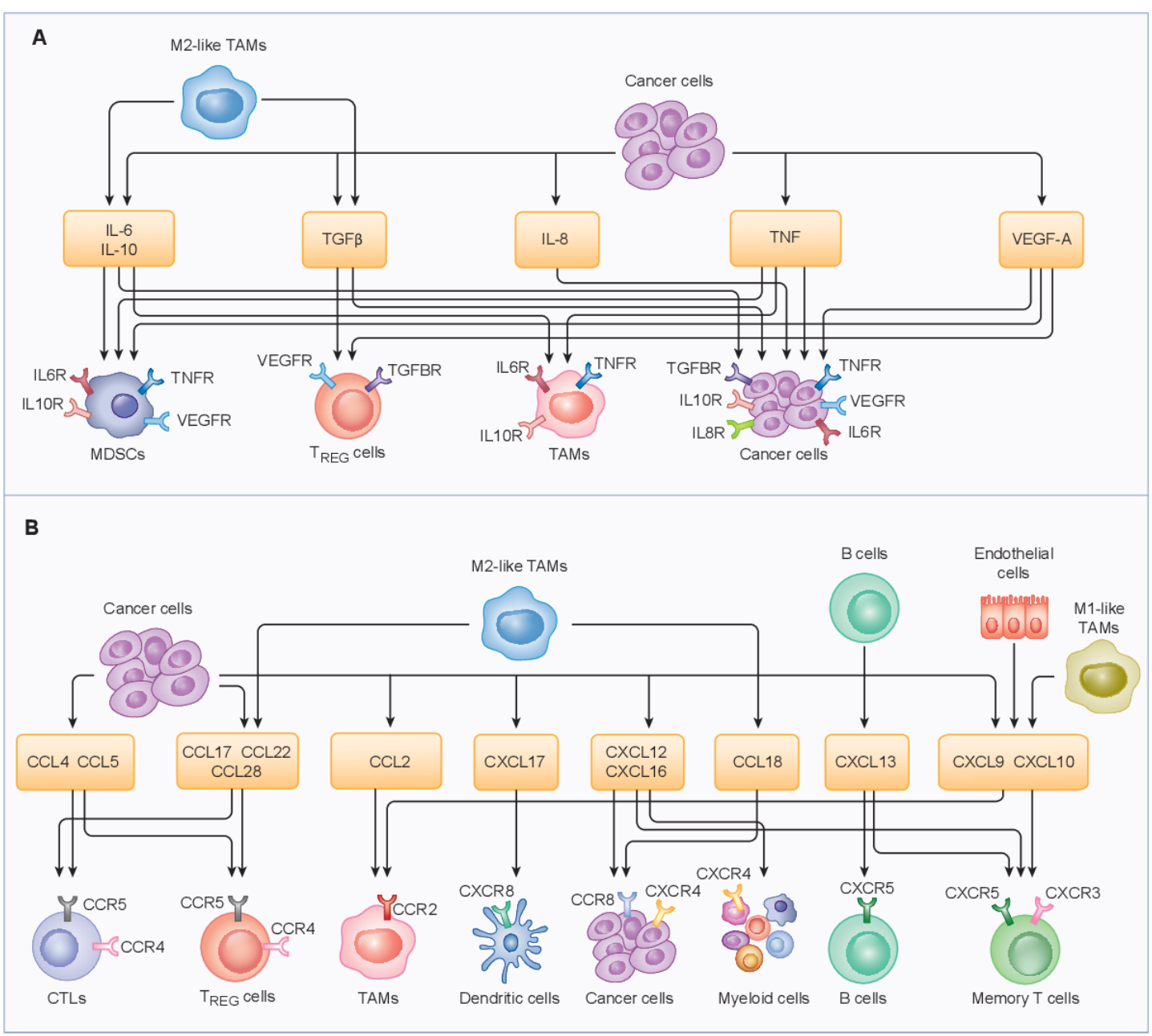

Figure 2 Cytokines and chemokines that coordinate the tumor microenvironment. Primary cytokines $(\mathrm{A})$ and chemokines (B) produced in the ovarian tumor microenvironment. The most prominent sources and major receptors are depicted. CCL, chemokine (C-C motif) ligand; CCR, C-C chemokine receptor; CXCL, chemokine (C-X-C motif) ligand; CXCR, C-X-C chemokine receptor; CTL, cytotoxic T lymphocyte; IL, interleukin; IL6R, interleukin 6 receptor; MDSC, myeloid-derived suppressor cell; NK, natural killer; pDC, plasmacytoid dendritic cell; TAM, tumor-associated macrophage; TGFB1, transforming growth factor beta 1; TGFBR, transforming growth factor beta receptor; TNF, tumor necrosis factor; TNFR, tumor necrosis factor receptor; $\mathrm{T}_{\mathrm{REG}}$, regulatory T; VEGFA, vascular endothelial growth factor A; VEGFR, vascular endothelial growth factor receptor.

One potential approach to improving the efficacy of ICIs in patients with EOC relies on the use of multiple nonredundant ICIs as a combinatorial regimen. ${ }^{176}$ Supporting the validity of this approach, nivolumab combined with a CTLA-4-specific ICI (ipilimumab) has been associated with an ORR of $31.4 \%$ (vs $12.2 \%$ for nivolumab alone) in phase II clinical trials enrolling 100 patients with persistent or recurrent EOC. ${ }^{192}$ Based on these clinical findings and the preclinical data discussed above, current efforts are being refocused on targeting coinhibitory receptors other than CTLA-4 and PD-1, including (but not limited to) TIM-3, LAG3 and TIGIT (source https://www.clinicaltrials.gov). The results of these trials are urgently awaited.

\section{Angiogenesis inhibitors}

The anti-angiogenic drug bevacizumab, a humanized monoclonal antibody targeting VEGFA, has now been employed for first-line management of advanced EOC for more than 7 years. ${ }^{193}$ Based on preclinical findings from mouse models of EOC, bevacizumab is expected to synergize with ICIs, largely reflecting its ability to promote tumor infiltration by T cells. ${ }^{194}$ Consistent with this notion, bevacizumab in combination with nivolumab has been associated with improved ORR $(28.9 \%)$ and PFS (median 9.4 months) in women with relapsed EOC, an activity that was even more pronounced in patients with platinum-sensitive lesions. ${ }^{195}$ Similarly, an ICI specific to PD-L1 (durvalumab) combined with a PARP inhibitor (olaparib) and cediranib, a tyrosine kinase inhibitor with anti-angiogenic activity, achieved an ORR of $50 \%$ and a disease control rate of $75 \%$ in 12 randomized patients. ${ }^{196}$ However, the results from a recent phase III study evaluating the addition of atezolizumab (an ICI specific for PD-L1) to platinum-based chemotherapy and bevacizumab failed to support the use of ICIs for newly diagnosed stage III or IV EOCs. ${ }^{197}$ 


\section{PARP inhibitors}

PARP inhibitors have emerged as key therapeutic interventions for patients with EOC. ${ }^{198}$ Indeed, rather common germline mutations in BRCA1 and BRCA2, resulting in HR defects, make EOCs highly sensitive to PARP inhibitors. ${ }^{198}$ Thus, no less than three distinct PARP inhibitors (ie, niraparib, olaparib, and rucaparib) are currently approved for the treatment of recurrent, platinum-sensitive EOC as maintenance on platinum chemotherapy. ${ }^{199}$ Of note, PARP inhibitors have been shown to mediate multipronged immunostimulatory effects, largely reflecting their ability to inhibit DNA repair in malignant cells. ${ }^{200}$ and indicating the possibility for synergy with ICIs. ${ }^{201}$ Thus, PARP inhibitors might enhance the mutational load of EOCs as consequence of unrepaired DNA damage, favoring $\mathrm{T}$ cell infiltration, but also appear to drive robust type I IFN secretion downstream of cyclic GMP-AMP synthase and stimulator of IFN response cGAMP interactor 1 activation. ${ }^{202} 203$ Based on these preclinical findings, PARP inhibitors are currently being tested in combination with ICIs in more than 10 ongoing clinical trials. ${ }^{12}$ The results of this wave of investigation are highly anticipated.

\section{Tumor vaccines}

A variety of tumor-associated antigens (TAAs) that can be specifically targeted by vaccination strategies have been identified in EOC. ${ }^{204}$ Cancer/testis antigen 1B (CTAG1B, best known as NY-ESO-1) is one such antigen, and several NY-ESO-1-based vaccines have been shown to provide NY-ESO- ${ }^{+}$EOC patients with an OS advantage. ${ }^{205}$ However, vaccine-driven immunoediting may ultimately promote the selection of NY-ESO- $1^{-}$EOC cell clones and hence enable clinical relapse. An alternative approach for vaccination involves the use of mutated TAAs as targets. ${ }^{206}$ Although advantageous in some aspects, this approach does not circumvent the possible emergence of antigennegative malignant cell clones, indicating an advantage for vaccination strategies targeting multiple TAAs at the same time, such as DC-based vaccines. ${ }^{63}$ In this context, DCs from a patient with EOC must be provided either ex vivo or in vivo with a source of TAAs in the context of activation cues in the former setting followed by DC reinfusion into the patient. ${ }^{63}$ Such sources can be as diverse as recombinant full-length TAAs or epitopes thereof, TAA-encoding nucleic acids, autologous tumor lysates, and allogeneic cancer cell lysates. Results from a number of clinical trials testing ex vivo DC-based vaccines in women with EOC demonstrate that this approach is well tolerated and associated with at least some activity. ${ }^{63} 207$ Moreover, in consideration of their mechanism of action, DC-based vaccines are expected to synergize with other immunotherapeutic interventions, such as ICI-based immunotherapy and adoptive $\mathrm{T}$ cell transfer (ACT). ${ }^{208}$ Nonetheless, no clinical trial is currently investigating a DC-based vaccine combined with ICIs or ACT in patients with EOC, an entire line of clinical investigation that is urgently awaited.

\section{Adoptive T cell transfer}

ACT represents a personalized immunotherapy based on autologous TILs expanded ex vivo and reintroduced into patients together with high-dose IL-2 on lymphodepletion. ${ }^{209}$ ACT has demonstrated considerable potency in patients with metastatic melanoma but limited success in women with EOC, potentially due to the strong immunosuppressive networks at play in the ovarian TME or suboptimal TIL expansion ex vivo. ${ }^{210}$ Several pilot and phase I/II clinical studies are currently open to investigating the therapeutic profile of ACT in women with advanced EOC. ${ }^{9}$ That said, available results from a pilot study enrolling six patients with advanced EOC suggest that ACT is primary active on existing target lesions but fails to control distant progression, ${ }^{211}$ potentially linked to TIL exhaustion, insufficient expansion or intralesion/ interlesion heterogeneity. ${ }^{212}$

\section{Chimeric antigens receptor-T cells and TCR therapy}

Chimeric antigens receptors (CARs) are fusion proteins engineered into $T$ cells for them to recognize specific antigens independent on MHC presentation. ${ }^{213}$ CAR-T cell therapy has achieved unprecedented success in the treatment of hematological malignancies such as relapsed/ refractory B-cell leukemia and lymphoma. ${ }^{213}$ However, a similar success has not been witnessed in patients with solid tumors, due to variety of obstacles. ${ }^{214}$ In line with this notion, a phase I study evaluating the safety and efficacy of first-generation of CAR-T cells targeting the folate receptor alpha (FOLR1) in patients with metastatic EOC documented limited efficacy. ${ }^{215}$ Current efforts are focusing on increasing CAR-T cell potency, with a particular interest around promoting CAR-T cells infiltration and intratumoral persistence. ${ }^{216} 217$ Despite these and other limitations, numerous early phase clinical trials are currently testing CAR-T cells with a variety of specificities in women with EOC (source https://www.clinicaltrials. gov). In this setting, a recent case report documented some therapeutic benefit (partial response and inhibition of hepatic progression) in a patient with metastatic EOC receiving CAR-T cells targeting mesothelin (MSLN) and engineered to secrete a PD-1-blocking single-chain fragment in combination with apatinib. ${ }^{218}$ These results suggest a novel therapeutic strategy for EOC and a Phase I study investigating this possibility is ongoing (NCT04503980). In similar line, T cells engineered by viral vectors to express the TCR gene with defined specificity (TCR-T cells) targeting NY-ESO-1 (NCT01567891, NCT03017131), MUC16 (NCT02498912), MAGE-A4 (NCT03132922) and neoantigens (NCT03412877) are tested in early phase clinical studies in EOC patients.

\section{Oncolytic virus therapy}

An alternative strategy to resolve immunosuppression is administer oncolytic viruses (OVs) directly into the TME. ${ }^{219}$ OVs preferentially infect and replicate in malignant cells, culminating with cell lysis accompanied by the release of various cytokines and DAMPs in support 
Table 4 Potential immunotherapeutic strategies against ovarian carcinoma

\begin{tabular}{llll}
\hline TMB status & Immune contexture & Vascularity & Potential immunotherapy \\
\hline High & High & Low & ICls \\
High & High & High & ICls + antiangiogenic agents \\
High & Low & Low & PARPi + antiangiogenic agents \\
Low & Low & Low & Immunogenic chemotherapy + DC-based therapy \\
Low & Low & Low & T-cell-based therapies (CAR-T cells, TILs) \\
Low & Low & Low & Vaccines (DC-based therapy) \\
Low & Low & PARPs + ICls \\
\hline
\end{tabular}

CAR-T cell, chimeric antigen receptor T cell; DC, dendritic cell; ICI, immune checkpoint inhibitor; PARPi, poly (ADP-ribose) polymerase inhibitor; TILs, tumor-infiltrating lymphocytes; TMB, Tumor mutational burden.

of tumor-targeting immunity. ${ }^{219}$ Indeed, talimogene laherparepvec (T-VEC) - the first OV approved by the US Food and Drug Administration-mediated multiple immunomodulatory functions, including the GM-CSFdependent recruitment, maturation, and activation of APCs culminating with the initiation of robust $\mathrm{T}$ cell responses with systemic outreach. ${ }^{220}$ Along similar lines, the oncolytic adenovirus AD5/3 has recently been shown to restore immunostimulation in the EOC microenvironment along with increased infiltration by CTLs. ${ }^{221}$ Therefore, OVs represent a promising combinatorial partner for other immunotherapeutic regimens in the management of solid tumors including EOC. For instance, T-VEC in combination with ICIs showed promising results in early phase clinical trials enrolling melanoma patients. ${ }^{222}$

\section{CONCLUDING REMARKS}

Immunotherapy with ICIs has revolutionized the management of multiple tumor types, creating enormous expectations around the possibility of harnessing the patient immune system against EOC. However, the clinical benefit of ICIs as standalone immunotherapeutic interventions in women EOC is limited. This may reflect limited preexisting immunity and/or the existence of robust immunosuppressive pathways in the EOC microenvironment.

In line with this notion, the findings discussed herein demonstrate that pre-existing immunity in the ovarian TME has a major impact on the sensitivity of EOC to (immuno)therapy, ${ }^{40}$ calling for the identification of immune biomarkers to integrate into common diagnostic assessments and guide treatment selection (table 4). For instance, women with highly infiltrated EOCs (so-called 'hot' tumors with an elevated immunoscore) may benefit from ICI-based immunotherapy or ACT, whereas individuals with an intermediate degree of immune infiltration are expected to respond to agents that stimulate $\mathrm{CD} 8^{+} \mathrm{T}$ cell infiltration (table 4). So-called 'cold' tumors which are characterized by a low immunoscore, remain the most challenging to eradicate and hence are associated with poor prognosis.

A potential strategy to overcome the lack of pre-existing immunity in EOC is to combine a priming therapy that enhances T cell responses, such as DC-based vaccination, or strategies that turn the tumor into an in situ vaccine, such as RT, using an approach that either removes immunosuppressive cues (eg, ICI-based immunotherapy, TAM depletion) or provides immunostimulatory signals. ${ }^{10}$ Moreover, accumulating preclinical and clinical evidence indicates that epigenetic modifiers, including DNA demethylating agents and some chemotherapeutics, can stimulate anticancer immunity by various mechanisms, including the (1) selective depletion of immunosuppressive cells; (2) lymphodepletion associated with renovation of the patient immunological repertoire and (3) activation of immune effector cells and hence may be beneficial in patients with low or absent TILs (table 4). Similarly, immunogenic chemotherapeutics such as doxorubicin and paclitaxel, antiangiogenic drugs and PARP inhibitors stand out as promising partners for ICIs in the management of patients with 'cold' EOC.

We surmise that rationally designed combinations of conventional and immunotherapeutic agents will be critical to unlock immunosuppression in the EOC microenvironment in support of clinical efficacy. Preclinical studies in immunocompetent EOC identifying not only the agents to be used in such combinations, but also their optimal administration schedule ${ }^{223}$ are urgently required to translate an expanding literature on the immune contexture of EOC into clinically relevant therapeutic strategies.

\footnotetext{
Author affiliations

${ }^{1}$ Sotio Biotech, Prague, Czech Republic

${ }^{2}$ Department of Immunology, Charles University, 2nd Faculty of Medicine and University Hospital Motol, Prague, Czech Republic

${ }^{3}$ Department of Oncology, Laboratory of Tumor Immunology and Immunotherapy, Leuven Cancer Institute, KU Leuven, Leuven, Belgium

${ }^{4}$ UCLA David Geffen School of Medicine and Jonsson Comprehensive Cancer Center, University of California Los Angeles, Los Angeles, California, USA

${ }^{5}$ Gynecologic Oncology Center, Department of Obstetrics and Gynecology, 1st Faculty of Medicine, Charles University and General University Hospital, Prague, Czech Republic

${ }^{6}$ Division of Gynecological Oncology, Department of Obstetrics and Gynecology, University Hospital Leuven, Leuven, Belgium

${ }^{7}$ Department of Radiation Oncology, Weill Cornell Medical College, New York, NY, USA

${ }^{8}$ Sandra and Edward Meyer Cancer Center, New York, NY, USA
} 
${ }^{9} \mathrm{Caryl}$ and Israel Englander Institute for Precision Medicine, New York, NY, USA

Contributors All authors listed have made substantial, direct and intellectual contributions to the work and approved it for publication.

Funding The authors have not declared a specific grant for this research from any funding agency in the public, commercial or not-for-profit sectors.

Competing interests JF and RS are employees of Sotio Biotech a.S.; IV declares consulting for Astra Zeneca, Clovis Oncology, Carrick Therapeutics, Deciphera Pharmaceuticals, Elevar Therapeutics, F. Hoggmann-La Roche, Genmab, GSK, Immunogen, Jazzpharma, Mersana, Millennium Pharmaceuticals, MSD, Novocure, Octimet Oncology NV, Oncoinvent AS, Sotio a.s., Verastem Oncology, Zentalis; contracted research for Oncoinvent AS, Genmab; research funding from Amgen, Roche; LG declares research funding from Lytix and Phosplatin (completed) and speaker and/or advisory honoraria from Boehringer Ingelheim, Astra Zeneca, OmniSEQ, The Longevity Labs, Inzen, Onxeo, the Luke Heller TECPR2 Foundation; SO has patents for molecular signatures in ovarian cancer (US10253368 and EU2908913) and is funded by NCl (R01 CA208753) and VA (VA-ORD BX004974) grants. AC declares consulting for SOTI0; contracted research for Novocure and Oncoinvent.

Patient consent for publication Not applicable.

Provenance and peer review Not commissioned; externally peer reviewed.

Open access This is an open access article distributed in accordance with the Creative Commons Attribution Non Commercial (CC BY-NC 4.0) license, which permits others to distribute, remix, adapt, build upon this work non-commercially, and license their derivative works on different terms, provided the original work is properly cited, appropriate credit is given, any changes made indicated, and the use is non-commercial. See http://creativecommons.org/licenses/by-nc/4.0/.

\section{ORCID iDs}

Jitka Fucikova http://orcid.org/0000-0002-8423-479X

An Coosemans http://orcid.org/0000-0002-7321-4339

David Cibula http://orcid.org/0000-0001-6387-9356

\section{REFERENCES}

1 Siegel RL, Miller KD, Fuchs HE, et al. Cancer statistics, 2021. CA Cancer J Clin 2021;71:7-33.

2 Colombo N, Sessa C, du Bois A, et al. ESMO-ESGO consensus conference recommendations on ovarian cancer: pathology and molecular biology, early and advanced stages, borderline tumours and recurrent diseaset. Ann Oncol 2019;30:672-705.

3 Milne K, Köbel M, Kalloger SE, et al. Systematic analysis of immune infiltrates in high-grade serous ovarian cancer reveals CD20, FOXP3 and TIA-1 as positive prognostic factors. PLoS One 2009;4:e6412.

4 Zhou J, Wu S-G, Wang J, et al. The effect of histological subtypes on outcomes of stage IV epithelial ovarian cancer. Front Oncol 2018;8:577.

5 Hu Z, Artibani M, Alsaadi A, et al. The repertoire of serous ovarian cancer non-genetic heterogeneity revealed by single-cell sequencing of normal fallopian tube epithelial cells. Cancer Cell 2020;37:226-42.

6 Gonzalez VD, Samusik N, Chen TJ, et al. Commonly occurring cell subsets in high-grade serous ovarian tumors identified by singlecell mass cytometry. Cell Rep 2018;22:1875-88.

7 Poveda A, Floquet A, Ledermann JA, et al. Olaparib tablets as maintenance therapy in patients with platinum-sensitive relapsed ovarian cancer and a BRCA1/2 mutation (SOLO2/ENGOT-Ov21): a final analysis of a double-blind, randomised, placebo-controlled, phase 3 trial. Lancet Oncol 2021;22:620-631.

8 Galluzzi L, Chan TA, Kroemer G, et al. The hallmarks of successful anticancer immunotherapy. Sci Trans/ Med 2018;10. doi:10.1126/ scitransImed.aat7807. [Epub ahead of print: 19 Sep 2018].

9 Kandalaft LE, Odunsi K, Coukos G. Immunotherapy in ovarian cancer: are we there yet? J Clin Oncol 2019;37:2460-71.

10 Galon J, Bruni D. Approaches to treat immune hot, altered and cold tumours with combination immunotherapies. Nat Rev Drug Discov 2019;18:197-218.

11 Hamanishi J, Mandai M, Ikeda T, et al. Safety and antitumor activity of anti-PD-1 antibody, nivolumab, in patients with platinum-resistant ovarian cancer. J Clin Oncol 2015;33:4015-22.

12 Yang Y, Yang Y, Yang J, et al. Tumor microenvironment in ovarian cancer: function and therapeutic strategy. Front Cell Dev Biol 2020;8:758
13 Krockenberger M, Dombrowski Y, Weidler C, et al. Macrophage migration inhibitory factor contributes to the immune escape of ovarian cancer by down-regulating NKG2D. J Immunol 2008:180:7338-48.

14 Horikawa N, Abiko K, Matsumura N, et al. Expression of vascular endothelial growth factor in ovarian cancer inhibits tumor immunity through the accumulation of myeloid-derived suppressor cells. Clin Cancer Res 2017;23:587-99.

15 Tanizaki Y, Kobayashi A, Toujima S, et al. Indoleamine 2,3-dioxygenase promotes peritoneal metastasis of ovarian cancer by inducing an immunosuppressive environment. Cancer Sci 2014;105:966-73.

16 Baert T, Vankerckhoven A, Riva M, et al. Myeloid derived suppressor cells: key drivers of immunosuppression in ovarian cancer. Front Immunol 2019;10:1273.

17 Conrad C, Gregorio J, Wang Y-H, et al. Plasmacytoid dendritic cells promote immunosuppression in ovarian cancer via ICOS costimulation of Foxp3(+) T-regulatory cells. Cancer Res 2012;72:5240-9.

18 Labidi-Galy SI, Treilleux I, Goddard-Leon S, et al. Plasmacytoid dendritic cells infiltrating ovarian cancer are associated with poor prognosis. Oncoimmunology 2012;1:380-2.

19 Etzerodt A, Moulin M, Doktor TK, et al. Tissue-Resident macrophages in omentum promote metastatic spread of ovarian cancer. J Exp Med 2020;217. doi:10.1084/jem.20191869. [Epub ahead of print: 06 Apr 2020].

20 Hensler M, Kasikova L, Fiser K, et al. M2-Like macrophages dictate clinically relevant immunosuppression in metastatic ovarian cancer. $J$ Immunother Cancer 2020;8.

21 Truxova I, Kasikova L, Hensler M, et al. Mature dendritic cells correlate with favorable immune infiltrate and improved prognosis in ovarian carcinoma patients. J Immunother Cancer 2018;6:139.

22 Santoiemma PP, Powell DJ. Tumor infiltrating lymphocytes in ovarian cancer. Cancer Biol Ther 2015;16:807-20. doi:10.1080/1538 4047.2015.1040960

23 Pearce OMT, Delaine-Smith RM, Maniati E, et al. Deconstruction of a metastatic tumor microenvironment reveals a common matrix response in human cancers. Cancer Discov 2018;8:304-19.

24 Hornburg M, Desbois M, Lu S, et al. Single-Cell dissection of cellular components and interactions shaping the tumor immune phenotypes in ovarian cancer. Cancer Cell 2021;39:928-44.

25 Izar B, Tirosh I, Stover EH, et al. A single-cell landscape of highgrade serous ovarian cancer. Nat Med 2020;26:1271-9.

26 Olalekan S, Xie B, Back R, et al. Characterizing the tumor microenvironment of metastatic ovarian cancer by single-cell transcriptomics. Cell Rep 2021;35:109165.

27 Hamanishi J, Mandai M, Abiko K, et al. The comprehensive assessment of local immune status of ovarian cancer by the clustering of multiple immune factors. Clin Immunol 2011:141:338-47

28 Hwang W-T, Adams SF, Tahirovic E, et al. Prognostic significance of tumor-infiltrating T cells in ovarian cancer: a meta-analysis. Gynecol Oncol 2012;124:192-8.

29 Leffers N, Gooden MJM, de Jong RA, et al. Prognostic significance of tumor-infiltrating T-lymphocytes in primary and metastatic lesions of advanced stage ovarian cancer. Cancer Immunol Immunother 2009:58:449-59.

30 Sato E, Olson SH, Ahn J, et al. Intraepithelial CD8+ tumor-infiltrating lymphocytes and a high CD8+/regulatory $T$ cell ratio are associated with favorable prognosis in ovarian cancer. Proc Natl Acad Sci U S A 2005; 102:18538-43.

31 Stumpf M, Hasenburg A, Riener M-O, et al. Intraepithelial CD8positive T lymphocytes predict survival for patients with serous stage III ovarian carcinomas: relevance of clonal selection of T lymphocytes. Br J Cancer 2009;101:1513-21.

32 Wang W, Kryczek I, Dostál L, et al. Effector T cells abrogate Stroma-Mediated chemoresistance in ovarian cancer. Cell 2016;165:1092-105.

33 Webb JR, Milne K, Watson P, et al. Tumor-Infiltrating lymphocytes expressing the tissue resident memory marker CD103 are associated with increased survival in high-grade serous ovarian cancer. Clin Cancer Res 2014;20:434-44.

34 Bachmayr-Heyda A, Aust S, Heinze G, et al. Prognostic impact of tumor infiltrating CD8+ T cells in association with cell proliferation in ovarian cancer patients--a study of the OVCAD consortium. BMC Cancer 2013;13:422.

35 Hamanishi J, Mandai M, Iwasaki M, et al. Programmed cell death 1 ligand 1 and tumor-infiltrating CD8+ T lymphocytes are prognostic factors of human ovarian cancer. Proc Natl Acad Sci U S A 2007:104:3360-5. 
36 Santoiemma PP, Reyes C, Wang L-P, et al. Systematic evaluation of multiple immune markers reveals prognostic factors in ovarian cancer. Gynecol Oncol 2016;143:120-7.

37 Hermans C, Anz D, Engel J, et al. Analysis of Foxp3+ T-regulatory cells and CD8+ T-cells in ovarian carcinoma: location and tumor infiltration patterns are key prognostic markers. PLoS One 2014;9:e111757.

38 Barnett JC, Bean SM, Whitaker RS, et al. Ovarian cancer tumor infiltrating T-regulatory $(\mathrm{T}(\mathrm{reg}))$ cells are associated with a metastatic phenotype. Gynecol Oncol 2010;116:556-62.

39 Henriksen JR, Donskov F, Waldstrøm M, et al. Favorable prognostic impact of natural killer cells and T cells in high-grade serous ovarian carcinoma. Acta Oncol 2020;59:652-9.

40 Zhang L, Conejo-Garcia JR, Katsaros D, et al. Intratumoral T cells, recurrence, and survival in epithelial ovarian cancer. $N$ Engl J Med 2003;348:203-13

41 Clarke B, Tinker AV, Lee C-H, et al. Intraepithelial T cells and prognosis in ovarian carcinoma: novel associations with stage, tumor type, and BRCA1 loss. Mod Pathol 2009;22:393-402.

42 Zhang Z, Huang J, Zhang C, et al. Infiltration of dendritic cells and T lymphocytes predicts favorable outcome in epithelial ovarian cancer. Cancer Gene Ther 2015;22:198-206.

43 Lieber S, Reinartz S, Raifer $\mathrm{H}$, et al. Prognosis of ovarian cancer is associated with effector memory $\mathrm{CD}^{+} \mathrm{T}$ cell accumulation in ascites, CXCL9 levels and activation-triggered signal transduction in T cells. Oncoimmunology 2018;7:e1424672.

44 Ovarian Tumor Tissue Analysis (OTTA) Consortium, Goode EL, Block MS, et al. Dose-response association of CD8+ tumorinfiltrating lymphocytes and survival time in high-grade serous ovarian cancer. JAMA Oncol 2017;3:e173290. doi:10.1001/ jamaoncol.2017.3290

45 Fucikova J, Rakova J, Hensler M, et al. Tim-3 dictates functional orientation of the immune infiltrate in ovarian cancer. Clin Cancer Res 2019;25:4820-31.

46 Facciabene A, Motz GT, Coukos G. T-Regulatory cells: key players in tumor immune escape and angiogenesis. Cancer Res 2012;72:2162-71

47 Komdeur FL, Wouters MCA, Workel HH, et al. CD103+ intraepithelial T cells in high-grade serous ovarian cancer are phenotypically diverse TCR $\alpha \beta+C D 8 \alpha \beta+$ T cells that can be targeted for cancer immunotherapy. Oncotarget 2016;7:75130-44.

48 Chihara N, Madi A, Kondo T, et al. Induction and transcriptional regulation of the co-inhibitory gene module in T cells. Nature 2018;558:454-9.

49 Zhu C, Sakuishi K, Xiao S, et al. An IL-27/NFIL3 signalling axis drives Tim-3 and IL-10 expression and T-cell dysfunction. Nat Commun 2015;6:6072.

50 Wolf Y, Anderson AC, Kuchroo VK. Tim3 comes of age as an inhibitory receptor. Nat Rev Immunol 2020;20:173-85.

51 Togashi Y, Shitara K, Nishikawa H. Regulatory T cells in cancer immunosuppression - implications for anticancer therapy. Nat Rev Clin Oncol 2019;16:356-71.

52 Sakaguchi S, Mikami N, Wing JB, et al. Regulatory T cells and human disease. Annu Rev Immunol 2020;38:541-66.

53 Wolf $\mathrm{D}$, Wolf $\mathrm{AM}$, Rumpold $\mathrm{H}$, et al. The expression of the regulatory $\mathrm{T}$ cell-specific forkhead box transcription factor FOXP3 is associated with poor prognosis in ovarian cancer. Clin Cancer Res 2005;11:8326-31

54 Curiel TJ, Coukos G, Zou L, et al. Specific recruitment of regulatory $\mathrm{T}$ cells in ovarian carcinoma fosters immune privilege and predicts reduced survival. Nat Med 2004;10:942-9.

55 Shang B, Liu Y, Jiang S-juan, et al. Prognostic value of tumorinfiltrating Foxp3+ regulatory T cells in cancers: a systematic review and meta-analysis. Sci Rep 2015;5:15179.

56 Kryczek I, Wei S, Zhu G, et al. Relationship between B7-H4, regulatory $T$ cells, and patient outcome in human ovarian carcinoma. Cancer Res 2007;67:8900-5.

57 Knutson KL, Maurer MJ, Preston CC, et al. Regulatory T cells, inherited variation, and clinical outcome in epithelial ovarian cancer. Cancer Immunol Immunother 2015;64:1495-504.

58 Tanchot $\mathrm{C}$, Terme M, Pere $\mathrm{H}$, et al. Tumor-Infiltrating regulatory $\mathrm{T}$ cells: phenotype, role, mechanism of expansion in situ and clinical significance. Cancer Microenviron 2013;6:147-57.

59 Fialová A, Partlová S, Sojka L, et al. Dynamics of T-cell infiltration during the course of ovarian cancer: the gradual shift from a Th17 effector cell response to a predominant infiltration by regulatory T-cells. Int J Cancer 2013;132:1070-9.

60 Zhou J, Li X, Wu X, et al. Exosomes released from tumorassociated macrophages transfer miRNAs that induce a Treg/Th17 cell imbalance in epithelial ovarian cancer. Cancer Immunol Res 2018;6:1578-92.
61 Facciabene A, Peng X, Hagemann IS, et al. Tumour hypoxia promotes tolerance and angiogenesis via CCL28 and T(reg) cells. Nature 2011;475:226-30.

62 Toker A, Nguyen LT, Stone SC, et al. Regulatory T cells in ovarian cancer are characterized by a highly activated phenotype distinct from that in melanoma. Clin Cancer Res 2018;24:5685-96.

63 Wculek SK, Cueto FJ, Mujal AM, et al. Dendritic cells in cancer immunology and immunotherapy. Nat Rev Immunol 2020;20:7-24.

64 Martinek J, Wu T-C, Cadena D, et al. Interplay between dendritic cells and cancer cells. Int Rev Cell Mol Biol 2019;348:179-215.

65 Reinartz S, Schumann T, Finkernagel F, et al. Mixed-polarization phenotype of ascites-associated macrophages in human ovarian carcinoma: correlation of CD163 expression, cytokine levels and early relapse. Int J Cancer 2014;134:32-42.

66 Wu M, Chen X, Lou J, et al. TGF- $\beta 1$ contributes to CD8+ Treg induction through p38 MAPK signaling in ovarian cancer microenvironment. Oncotarget 2016;7:44534-44.

67 Cai DL, Jin L-P. Immune cell population in ovarian tumor microenvironment. J Cancer 2017;8:2915-23.

68 Chen F, Hou M, Ye F, et al. Ovarian cancer cells induce peripheral mature dendritic cells to differentiate into macrophagelike cells in vitro. Int J Gynecol Cancer 2009;19:1487-93.

69 Curiel TJ, Wei S, Dong H, et al. Blockade of B7-H1 improves myeloid dendritic cell-mediated antitumor immunity. Nat Med 2003;9:562-7.

70 Bronger H, Singer J, Windmüller C, et al. Cxcl9 and CXCL10 predict survival and are regulated by cyclooxygenase inhibition in advanced serous ovarian cancer. Br J Cancer 2016;115:553-63.

71 Amon L, Lehmann CHK, Baranska A, et al. Transcriptional control of dendritic cell development and functions. Int Rev Cell Mol Biol 2019;349:55-151.

72 Broz ML, Binnewies M, Boldajipour B, et al. Dissecting the tumor myeloid compartment reveals rare activating antigen-presenting cells critical for T cell immunity. Cancer Cell 2014;26:938.

73 Sautès-Fridman C, Petitprez F, Calderaro J, et al. Tertiary lymphoid structures in the era of cancer immunotherapy. Nat Rev Cancer 2019;19:307-25.

74 MacGregor HL, Garcia-Batres C, Sayad A, et al. Tumor cell expression of $\mathrm{B} 7-\mathrm{H} 4$ correlates with higher frequencies of tumorinfiltrating APCS and higher CXCL17 expression in human epithelial ovarian cancer. Oncoimmunology 2019;8:e1665460.

75 Leylek R, Idoyaga J. The versatile plasmacytoid dendritic cell: function, heterogeneity, and plasticity. Int Rev Cell Mol Biol 2019;349:177-211.

76 Demoulin S, Herfs M, Delvenne P, et al. Tumor microenvironment converts plasmacytoid dendritic cells into immunosuppressive/ tolerogenic cells: insight into the molecular mechanisms. J Leukoc Biol 2013;93:343-52

77 Labidi-Galy SI, Sisirak V, Meeus P, et al. Quantitative and functional alterations of plasmacytoid dendritic cells contribute to immune tolerance in ovarian cancer. Cancer Res 2011;71:5423-34.

78 Inaba $\mathrm{T}$, Ino K, Kajiyama $\mathrm{H}$, et al. Role of the immunosuppressive enzyme indoleamine 2,3-dioxygenase in the progression of ovarian carcinoma. Gynecol Oncol 2009;115:185-92.

79 Zou W, Machelon V, Coulomb-L'Hermin A, et al. Stromal-derived factor-1 in human tumors recruits and alters the function of plasmacytoid precursor dendritic cells. Nat Med 2001;7:1339-46.

80 Fucikova J, Palova-Jelinkova L, Bartunkova J, et al. Induction of tolerance and immunity by dendritic cells: mechanisms and clinical applications. Front Immunol 2019;10:2393.

81 Nielsen JS, Sahota RA, Milne K, et al. CD20+ tumor-infiltrating lymphocytes have an atypical CD27-memory phenotype and together with CD8+ T cells promote favorable prognosis in ovarian cancer. Clin Cancer Res 2012;18:3281-92.

82 Iglesia MD, Vincent BG, Parker JS, et al. Prognostic B-cell signatures using mRNA-seq in patients with subtype-specific breast and ovarian cancer. Clin Cancer Res 2014;20:3818-29.

83 Kroeger DR, Milne K, Nelson BH. Tumor-Infiltrating plasma cells are associated with tertiary lymphoid structures, cytolytic T-cell responses, and superior prognosis in ovarian cancer. Clin Cancer Res 2016;22:3005-15.

84 Zhu Y, Zhang Z, Jiang Z, et al. Cd38 predicts favorable prognosis by enhancing immune infiltration and antitumor immunity in the epithelial ovarian cancer microenvironment. Front Genet 2020;11:369.

85 Lundgren S, Berntsson J, Nodin B, et al. Prognostic impact of tumour-associated B cells and plasma cells in epithelial ovarian cancer. J Ovarian Res 2016;9:21.

86 Helmink BA, Reddy SM, Gao J, et al. B cells and tertiary lymphoid structures promote immunotherapy response. Nature 2020;577:549-55. 
87 Germain C, Gnjatic S, Tamzalit F, et al. Presence of B cells in tertiary lymphoid structures is associated with a protective immunity in patients with lung cancer. Am J Respir Crit Care Med 2014:189:832-44

88 Nelson BH. CD20+ B cells: the other tumor-infiltrating lymphocytes. $J$ Immunol 2010;185:4977-82.

89 Montfort A, Pearce O, Maniati E, et al. A strong B-cell response is part of the immune landscape in human high-grade serous ovarian metastases. Clin Cancer Res 2017;23:250-62.

90 Vitale I, Shema E, Loi S, et al. Intratumoral heterogeneity in cancer progression and response to immunotherapy. Nat Med 2021;27:212-24.

91 Vankerckhoven A, Wouters R, Mathivet T, et al. Opposite macrophage polarization in different subsets of ovarian cancer: observation from a pilot study. Cells 2020;9. doi:10.3390/ cells9020305. [Epub ahead of print: 27 Jan 2020].

92 Vitale I, Manic G, Coussens LM, et al. Macrophages and metabolism in the tumor microenvironment. Cell Metab 2019;30:36-50.

93 Cassetta L, Pollard JW. Targeting macrophages: therapeutic approaches in cancer. Nat Rev Drug Discov 2018;17:887-904.

94 Yin M, Li X, Tan S, et al. Tumor-Associated macrophages drive spheroid formation during early transcoelomic metastasis of ovarian cancer. J Clin Invest 2016;126:4157-73.

95 Yuan X, Zhang J, Li D, et al. Prognostic significance of tumorassociated macrophages in ovarian cancer: a meta-analysis. Gynecol Oncol 2017;147:181-7.

96 Le Page C, Marineau A, Bonza PK, et al. BTN3A2 expression in epithelial ovarian cancer is associated with higher tumor infiltrating $\mathrm{T}$ cells and a better prognosis. PLoS One 2012; 7:e38541.

97 Lan C, Huang X, Lin S, et al. Expression of M2-polarized macrophages is associated with poor prognosis for advanced epithelial ovarian cancer. Technol Cancer Res Treat 2013;12:259-67.

$98 \mathrm{He}$ Y-feng, Zhang M-ying, Wu X, et al. High MUC2 expression in ovarian cancer is inversely associated with the M1/M2 ratio of tumor-associated macrophages and patient survival time. PLoS One 2013;8:e79769.

99 Hagemann T, Robinson SC, Thompson RG, et al. Ovarian cancer cell-derived migration inhibitory factor enhances tumor growth, progression, and angiogenesis. Mol Cancer Ther 2007:6:1993-2002.

100 Zhou Y, Xu Y, Chen L, et al. B7-H6 expression correlates with cancer progression and patient's survival in human ovarian cancer. Int J Clin Exp Pathol 2015;8:9428-33.

101 Zhang M, He Y, Sun X, et al. A high M1/M2 ratio of tumorassociated macrophages is associated with extended survival in ovarian cancer patients. J Ovarian Res 2014;7:19.

102 Macciò A, Gramignano G, Cherchi MC, et al. Role of M1-polarized tumor-associated macrophages in the prognosis of advanced ovarian cancer patients. Sci Rep 2020;10:6096.

103 Guerriero JL. Macrophages: their untold story in T cell activation and function. Int Rev Cell Mol Biol 2019;342:73-93

104 Gharpure KM, Pradeep S, Sans M, et al. Fabp4 as a key determinant of metastatic potential of ovarian cancer. Nat Commun 2018;9:2923.

105 Hao J, Yan F, Zhang Y, et al. Expression of Adipocyte/Macrophage fatty acid-binding protein in tumor-associated macrophages promotes breast cancer progression. Cancer Res 2018;78:2343-55.

106 Nieman KM, Kenny HA, Penicka CV, et al. Adipocytes promote ovarian cancer metastasis and provide energy for rapid tumor growth. Nat Med 2011:17:1498-503.

107 Goossens P, Rodriguez-Vita J, Etzerodt A, et al. Membrane cholesterol efflux drives tumor-associated macrophage reprogramming and tumor progression. Cell Metab 2019;29:1376-89.

108 Veglia F, Sanseviero E, Gabrilovich DI. Myeloid-Derived suppressor cells in the era of increasing myeloid cell diversity. Nat Rev Immunol $2021 ; 21: 485-498$

109 Gabrilovich DI, Nagaraj S. Myeloid-Derived suppressor cells as regulators of the immune system. Nat Rev Immunol 2009;9:162-74.

110 Okła K, Czerwonka A, Wawruszak A, et al. Clinical relevance and immunosuppressive pattern of circulating and infiltrating subsets of myeloid-derived suppressor cells (MDSCs) in epithelial ovarian cancer. Front Immunol 2019;10:691.

111 Wu L, Deng Z, Peng Y, et al. Ascites-derived IL-6 and IL-10 synergistically expand $\mathrm{CD} 14^{+} \mathrm{HLA}^{-\mathrm{DR}^{-}}{ }^{-1 \text { low }}$ myeloid-derived suppressor cells in ovarian cancer patients. Oncotarget 2017;8:76843-56.

112 Rodríguez-Ubreva J, Català-Moll F, Obermajer N, et al. Prostaglandin E2 leads to the acquisition of DNMT3A-Dependent tolerogenic functions in human myeloid-derived suppressor cells. Cell Rep 2017;21:154-67.

113 Obermajer N, Muthuswamy R, Odunsi K, et al. PGE(2)-induced CXCL12 production and CXCR4 expression controls the accumulation of human MDSCs in ovarian cancer environment. Cancer Res 2011;71:7463-70.

114 Li X, Wang J, Wu W, et al. Myeloid-Derived suppressor cells promote epithelial ovarian cancer cell stemness by inducing the CSF2/p-STAT3 signalling pathway. Febs J 2020;287:5218-35.

115 Taki M, Abiko K, Baba T, et al. Snail promotes ovarian cancer progression by recruiting myeloid-derived suppressor cells via CXCR2 ligand upregulation. Nat Commun 2018;9:1685.

116 Komura N, Mabuchi S, Shimura K, et al. The role of myeloid-derived suppressor cells in increasing cancer stem-like cells and promoting PD-L1 expression in epithelial ovarian cancer. Cancer Immunol Immunother 2020;69:2477-99.

117 Okła K, Rajtak A, Czerwonka A, et al. Accumulation of bloodcirculating PD-L1-expressing M-MDSCs and monocytes/ macrophages in pretreatment ovarian cancer patients is associated with soluble PD-L1. J Trans/ Med 2020;18:220.

118 Li L, Wang L, Li J, et al. Metformin-Induced reduction of CD39 and CD73 blocks myeloid-derived suppressor cell activity in patients with ovarian cancer. Cancer Res 2018;78:1779-91.

119 Obermajer N, Wong JL, Edwards RP, et al. Induction and stability of human Th17 cells require endogenous NOS2 and cGMP-dependent no signaling. J Exp Med 2013;210:1433-45.

120 Wong JL, Obermajer N, Odunsi K, et al. Synergistic COX2 induction by IFN $\gamma$ and TNF $\alpha$ self-limits type- 1 immunity in the human tumor microenvironment. Cancer Immunol Res 2016;4:303-11.

121 Condamine T, Dominguez GA, Youn J-I, et al. Lectin-type oxidized LDL receptor-1 distinguishes population of human polymorphonuclear myeloid-derived suppressor cells in cancer patients. Sci Immunol 2016;1. doi:10.1126/sciimmunol.aaf8943. [Epub ahead of print: 05 Aug 2016].

122 Mabuchi S, Komura N, Sasano T, et al. Pretreatment tumorrelated leukocytosis misleads positron emission tomographycomputed tomography during lymph node staging in gynecological malignancies. Nat Commun 2020;11:1364.

123 Cui TX, Kryczek I, Zhao L, et al. Myeloid-Derived suppressor cells enhance stemness of cancer cells by inducing microRNA101 and suppressing the corepressor CtBP2. Immunity 2013;39:611-21.

124 Trillo-Tinoco J, Sierra RA, Mohamed E, et al. Ampk alpha-1 intrinsically regulates the function and differentiation of tumor myeloid-derived suppressor cells. Cancer Res 2019;79:5034-47.

125 Huntington ND, Cursons J, Rautela J. The cancer-natural killer cell immunity cycle. Nat Rev Cancer 2020;20:437-54

126 Cózar B, Greppi M, Carpentier S, et al. Tumor-Infiltrating natural killer cells. Cancer Discov 2021:11:34-44.

127 Hoogstad-van Evert JS, Maas RJ, van der Meer J, et al. Peritoneal NK cells are responsive to IL-15 and percentages are correlated with outcome in advanced ovarian cancer patients. Oncotarget 2018;9:34810-20

128 Nersesian S, Glazebrook H, Toulany J, et al. Naturally killing the silent killer: NK cell-based immunotherapy for ovarian cancer. Front Immunol 2019;10:10.

129 Yigit R, Massuger LFAG, Figdor CG, et al. Ovarian cancer creates a suppressive microenvironment to escape immune elimination. Gynecol Oncol 2010;117:366-72.

130 Krockenberger M, Kranke P, Häusler S, et al. Macrophage migration-inhibitory factor levels in serum of patients with ovarian cancer correlates with poor prognosis. Anticancer Res 2012;32:5233-8.

131 Pesce S, Tabellini G, Cantoni C, et al. B7-H6-mediated downregulation of $\mathrm{NKp30}$ in NK cells contributes to ovarian carcinoma immune escape. Oncoimmunology 2015;4:e1001224.

132 Böttcher JP, Bonavita E, Chakravarty P, et al. Nk cells stimulate recruitment of cdc1 into the tumor microenvironment promoting cancer immune control. Cell 2018;172:1022-37.

133 Wong JL, Berk E, Edwards RP, et al. IL-18-primed helper NK cells collaborate with dendritic cells to promote recruitment of effector CD8+ T cells to the tumor microenvironment. Cancer Res 2013;73:4653-62.

134 Sahai E, Astsaturov I, Cukierman E, et al. A framework for advancing our understanding of cancer-associated fibroblasts. Nat Rev Cancer 2020;20:174-86.

135 Dasari S, Fang Y, Mitra AK. Cancer associated fibroblasts: Naughty neighbors that drive ovarian cancer progression. Cancers 2018;10. doi:10.3390/cancers10110406. [Epub ahead of print: 29 Oct 2018].

136 Spaeth EL, Dembinski JL, Sasser AK, et al. Mesenchymal stem cell transition to tumor-associated fibroblasts contributes to 
fibrovascular network expansion and tumor progression. PLoS One 2009:4:e4992.

137 McLean K, Gong Y, Choi Y, et al. Human ovarian carcinomaassociated mesenchymal stem cells regulate cancer stem cells and tumorigenesis via altered BMP production. $J$ Clin Invest 2011;121:3206-19.

138 Mhawech-Fauceglia P, Wang D, Samrao D, et al. Clinical implications of marker expression of carcinoma-associated fibroblasts (CAFs) in patients with epithelial ovarian carcinoma after treatment with neoadjuvant chemotherapy. Cancer Microenviron 2014;7:33-9.

139 Sun Y, Fan X, Zhang Q, et al. Cancer-Associated fibroblasts secrete FGF-1 to promote ovarian proliferation, migration, and invasion through the activation of FGF-1/FGFR4 signaling. Tumour Biol 2017;39:1010428317712592.

140 Vitale I, Manic G, Galassi C, et al. Stress responses in stromal cells and tumor homeostasis. Pharmacol Ther 2019;200:55-68.

141 Schauer IG, Sood AK, Mok S, et al. Cancer-Associated fibroblasts and their putative role in potentiating the initiation and development of epithelial ovarian cancer. Neoplasia 2011;13:393-405.

142 Schauer IG, Zhang J, Xing Z, et al. Interleukin-1 $\beta$ promotes ovarian tumorigenesis through a p53/NF- $\mathrm{kB}$-mediated inflammatory response in stromal fibroblasts. Neoplasia 2013;15:409-20.

143 Mitra AK, Zillhardt M, Hua Y, et al. Micrornas reprogram normal fibroblasts into cancer-associated fibroblasts in ovarian cancer. Cancer Discov 2012;2:1100-8.

144 Curtis M, Kenny HA, Ashcroft B, et al. Fibroblasts mobilize tumor cell glycogen to promote proliferation and metastasis. Cell Metab 2019;29:141-55.

145 Tsukishiro S, Suzumori N, Nishikawa H, et al. Elevated serum RANTES levels in patients with ovarian cancer correlate with the extent of the disorder. Gynecol Oncol 2006;102:542-5.

146 Yeung T-L, Leung CS, Wong K-K, et al. TGF- $\beta$ modulates ovarian cancer invasion by upregulating CAF-derived versican in the tumor microenvironment. Cancer Res 2013;73:5016-28.

147 Orimo A, Gupta PB, Sgroi DC, et al. Stromal fibroblasts present in invasive human breast carcinomas promote tumor growth and angiogenesis through elevated SDF-1/CXCL12 secretion. Cell 2005; 121:335-48

148 Ladanyi A, Mukherjee A, Kenny HA, et al. Adipocyte-induced CD36 expression drives ovarian cancer progression and metastasis. Oncogene 2018;37:2285-301.

149 Leung CS, Yeung T-L, Yip K-P, et al. Cancer-Associated fibroblasts regulate endothelial adhesion protein LPP to promote ovarian cancer chemoresistance. J Clin Invest 2018;128:589-606.

150 Yan H, Guo B-Y, Zhang S. Cancer-Associated fibroblasts attenuate cisplatin-induced apoptosis in ovarian cancer cells by promoting STAT3 signaling. Biochem Biophys Res Commun 2016;470:947-54.

151 Monteran L, Erez N. The dark side of fibroblasts: cancer-associated fibroblasts as mediators of immunosuppression in the tumor microenvironment. Front Immunol 2019;10:10.

152 Lakins MA, Ghorani E, Munir H, et al. Cancer-associated fibroblasts induce antigen-specific deletion of $\mathrm{CD} 8{ }^{+} \mathrm{T}$ Cells to protect tumour cells. Nat Commun 2018;9:948.

153 Ko SY, Barengo N, Ladanyi A, et al. Hoxa9 promotes ovarian cancer growth by stimulating cancer-associated fibroblasts. J Clin Invest 2012;122:3603-17.

154 Li W, Zhang X, Wang J, et al. Tgf $\beta 1$ in fibroblasts-derived exosomes promotes epithelial-mesenchymal transition of ovarian cancer cells. Oncotarget 2017;8:96035-47.

155 Zsiros E, Duttagupta P, Dangaj D, et al. The ovarian cancer chemokine landscape is conducive to homing of Vaccine-Primed and CD3/CD28-Costimulated T cells prepared for adoptive therapy. Clin Cancer Res 2015;21:2840-50.

156 Kulbe H, Chakravarty P, Leinster DA, et al. A dynamic inflammatory cytokine network in the human ovarian cancer microenvironment. Cancer Res 2012;72:66-75.

157 Coward J, Kulbe H, Chakravarty P, et al. Interleukin-6 as a therapeutic target in human ovarian cancer. Clin Cancer Res 2011;17:6083-96.

158 Nilsson MB, Langley RR, Fidler IJ. Interleukin-6, secreted by human ovarian carcinoma cells, is a potent proangiogenic cytokine. Cancer Res 2005;65:10794-800.

159 Isobe A, Sawada K, Kinose Y, et al. Interleukin 6 receptor is an independent prognostic factor and a potential therapeutic target of ovarian cancer. PLoS One 2015;10:e0118080.

160 Browning L, Patel MR, Horvath EB, et al. II-6 and ovarian cancer: inflammatory cytokines in promotion of metastasis. Cancer Manag Res 2018;10:6685-93.
161 Saini U, Naidu S, EINaggar AC, et al. Elevated STAT3 expression in ovarian cancer ascites promotes invasion and metastasis: a potential therapeutic target. Oncogene 2017;36:168-81.

162 Colomiere M, Ward AC, Riley C, et al. Cross talk of signals between EGFR and IL-6R through JAK2/STAT3 mediate epithelialmesenchymal transition in ovarian carcinomas. Br J Cancer 2009;100:134-44.

163 Alsina-Sanchis E, Figueras A, Lahiguera Álvaro, et al. The TGF $\beta$ pathway stimulates ovarian cancer cell proliferation by increasing IGF1R levels. Int J Cancer 2016;139:1894-903.

164 Kassim SK, El-Salahy EM, Fayed ST, et al. Vascular endothelial growth factor and interleukin-8 are associated with poor prognosis in epithelial ovarian cancer patients. Clin Biochem 2004;37:363-9.

165 Charles KA, Kulbe H, Soper R, et al. The tumor-promoting actions of TNF-alpha involve TNFR1 and IL-17 in ovarian cancer in mice and humans. J Clin Invest 2009;119:3011-23.

166 Coosemans AN, Baert T, D'Heygere V, et al. Increased immunosuppression is related to increased amounts of ascites and inferior prognosis in ovarian cancer. Anticancer Res 2019:39:5953-62

167 Rao S, Gharib K, Han A. Cancer immunosurveillance by T cells. Int Rev Cell Mol Biol 2019;342:149-73.

168 Kolomeyevskaya N, Eng KH, Khan ANH, et al. Cytokine profiling of ascites at primary surgery identifies an interaction of tumor necrosis factor- $\alpha$ and interleukin- 6 in predicting reduced progression-free survival in epithelial ovarian cancer. Gynecol Oncol 2015;138:352-7.

169 Mir H, Kaur G, Kapur N, et al. Higher CXCL16 exodomain is associated with aggressive ovarian cancer and promotes the disease by CXCR6 activation and MMP modulation. Sci Rep 2019;9:2527.

170 Negus RP, Stamp GW, Relf MG, et al. The detection and localization of monocyte chemoattractant protein-1 (MCP-1) in human ovarian cancer. J Clin Invest 1995:95:2391-6.

171 Nesbeth YC, Martinez DG, Toraya S, et al. Cd4+ T cells elicit host immune responses to $\mathrm{MHC}$ class II-negative ovarian cancer through CCL5 secretion and CD40-mediated licensing of dendritic cells. $J$ Immunol 2010;184:5654-62.

172 Franciszkiewicz K, Boutet M, Gauthier L, et al. Synaptic release of CCL5 storage vesicles triggers CXCR4 surface expression promoting CTL migration in response to CXCL12. J Immunol 2014;193:4952-61.

173 Jiang Y-P, Wu X-H, Shi B, et al. Expression of chemokine CXCL12 and its receptor CXCR4 in human epithelial ovarian cancer: an independent prognostic factor for tumor progression. Gynecol Oncol 2006;103:226-33.

174 Lane D, Matte I, Laplante C, et al. Ccl18 from ascites promotes ovarian cancer cell migration through proline-rich tyrosine kinase 2 signaling. Mol Cancer 2016;15:58.

175 Wang Q, Tang Y, Yu H, et al. Ccl18 from tumor-cells promotes epithelial ovarian cancer metastasis via mTOR signaling pathway. Mol Carcinog 2016;55:1688-99.

176 Huang R-Y, Francois A, McGray AR, et al. Compensatory upregulation of PD-1, LAG-3, and CTLA-4 limits the efficacy of single-agent checkpoint blockade in metastatic ovarian cancer. Oncoimmunology 2017;6:e1249561.

177 Sha D, Jin Z, Budczies J, et al. Tumor mutational burden as a predictive biomarker in solid tumors. Cancer Discov 2020;10:1808-25.

178 Galluzzi L, Humeau J, Buqué A, et al. Immunostimulation with chemotherapy in the era of immune checkpoint inhibitors. Nat Rev Clin Oncol 2020;17:725-41.

179 Lhuillier C, Rudqvist N-P, Yamazaki T, et al. Radiotherapy-exposed CD8+ and CD4+ neoantigens enhance tumor control. J Clin Invest 2021;131. doi:10.1172/JCl138740. [Epub ahead of print: 01 Mar 2021].

180 Galluzzi L, Vitale I, Warren S, et al. Consensus guidelines for the definition, detection and interpretation of immunogenic cell death. $J$ Immunother Cancer 2020;8:e00337. doi:10.1136/jitc-2019-000337

181 Kasikova L, Hensler M, Truxova I, et al. Calreticulin exposure correlates with robust adaptive antitumor immunity and favorable prognosis in ovarian carcinoma patients. $J$ Immunother Cancer 2019;7:312.

182 Fucikova J, Spisek R, Kroemer G, et al. Calreticulin and cancer. Cell Res 2021;31:5-16.

183 Disis ML, Taylor MH, Kelly K, et al. Efficacy and safety of Avelumab for patients with recurrent or refractory ovarian cancer: phase $1 \mathrm{~B}$ results from the javelin solid tumor trial. JAMA Oncol 2019:5:393-401.

184 Pujade-Lauraine E, Fujiwara K, Dychter SS, et al. Avelumab (antiPD-L1) in platinum-resistant/refractory ovarian cancer: javelin ovarian 200 phase III study design. Future Oncol 2018;14:2103-13. 
185 Monk BJ, Brady MF, Aghajanian C, et al. A phase 2, randomized, double-blind, placebo- controlled study of chemo-immunotherapy combination using motolimod with pegylated liposomal doxorubicin in recurrent or persistent ovarian cancer: a Gynecologic Oncology Group partners study. Ann Oncol 2017;28:996-1004.

186 Senovilla L, Vitale I, Martins I, et al. An immunosurveillance mechanism controls cancer cell ploidy. Science 2012;337:1678-84.

187 Wanderley CW, Colón DF, Luiz JPM, et al. Paclitaxel reduces tumor growth by reprogramming tumor-associated macrophages to an M1 profile in a TLR4-dependent manner. Cancer Res 2018;78:5891-900.

188 Noordam L, Kaijen MEH, Bezemer K, et al. Low-Dose cyclophosphamide depletes circulating naïve and activated regulatory T cells in malignant pleural mesothelioma patients synergistically treated with dendritic cell-based immunotherapy. Oncoimmunology 2018;7:e1474318.

189 Zsiros E, Lynam S, Attwood KM, et al. Efficacy and safety of pembrolizumab in combination with bevacizumab and oral metronomic cyclophosphamide in the treatment of recurrent ovarian cancer: a phase 2 nonrandomized clinical trial. JAMA Oncol 2021;7:78-85

190 Yang M, Lu J, Zhang G, et al. Cxcl13 shapes immunoactive tumor microenvironment and enhances the efficacy of PD-1 checkpoint blockade in high-grade serous ovarian cancer. $J$ Immunother Cancer 2021;9.

191 Matulonis UA, Shapira-Frommer R, Santin AD, et al. Antitumor activity and safety of pembrolizumab in patients with advanced recurrent ovarian cancer: results from the phase II KEYNOTE-100 study. Ann Oncol 2019;30:1080-7.

192 Zamarin D, Burger RA, Sill MW, et al. Randomized phase II trial of nivolumab versus nivolumab and ipilimumab for recurrent or persistent ovarian cancer: an NRG oncology study. J Clin Oncol 2020;38:1814-23.

193 Rossi L, Verrico M, Zaccarelli E, et al. Bevacizumab in ovarian cancer: a critical review of phase III studies. Oncotarget 2017:8:12389-405.

194 Shrimali RK, Yu Z, Theoret MR, et al. Antiangiogenic agents can increase lymphocyte infiltration into tumor and enhance the effectiveness of adoptive immunotherapy of cancer. Cancer Res 2010;70:6171-80

195 Liu JF, Herold C, Gray KP, et al. Assessment of combined nivolumab and bevacizumab in relapsed ovarian cancer: a phase 2 clinical trial. JAMA Oncol 2019;5:1731-8.

196 Lee J-M, Cimino-Mathews A, Peer CJ, et al. Safety and clinical activity of the programmed Death-Ligand 1 inhibitor Durvalumab in combination with poly (ADP-ribose) polymerase inhibitor olaparib or vascular endothelial growth factor receptor 1-3 inhibitor cediranib in women's cancers: a dose-escalation, phase I study. J Clin Oncol 2017;35:2193-202.

197 Moore KN, Bookman M, Sehouli J, et al. Atezolizumab, bevacizumab, and chemotherapy for newly diagnosed stage III or IV ovarian cancer: placebo-controlled randomized phase III trial (IMagyn050/GOG 3015/ENGOT-OV39). J Clin Oncol 2021;39:1842-55. doi:10.1200/JCO.21.00306

198 Mirza MR, Coleman RL, González-Martín A, et al. The forefront of ovarian cancer therapy: update on PARP inhibitors. Ann Oncol 2020;31:1148-59.

199 Mirza MR, Monk BJ, Herrstedt J, et al. Niraparib maintenance therapy in platinum-sensitive, recurrent ovarian cancer. N Engl $J$ Med 2016;375:2154-64.

200 Petroni G, Buqué A, Zitvogel L, et al. Immunomodulation by targeted anticancer agents. Cancer Cell 2021;39:310-45.

201 Konstantinopoulos PA, Waggoner S, Vidal GA, et al. SingleArm phases 1 and 2 trial of Niraparib in combination with pembrolizumab in patients with recurrent platinum-resistant ovarian carcinoma. JAMA Oncol 2019;5:1141-9.

202 Yamazaki T, Kirchmair A, Sato A, et al. Mitochondrial DNA drives abscopal responses to radiation that are inhibited by autophagy. Nat Immunol 2020;21:1160-71.
203 Chabanon RM, Muirhead G, Krastev DB, et al. Parp inhibition enhances tumor cell-intrinsic immunity in ERCC1-deficient nonsmall cell lung cancer. J Clin Invest 2019;129:1211-28.

204 Sprooten J, Ceusters J, Coosemans A, et al. Trial Watch: dendritic cell vaccination for cancer immunotherapy. Oncoimmunology 2019;8:e1638212.

205 Odunsi K, Matsuzaki J, James SR, et al. Epigenetic potentiation of NY-ESO-1 vaccine therapy in human ovarian cancer. Cancer Immunol Res 2014;2:37-49.

206 Chow S, Berek JS, Dorigo O. Development of therapeutic vaccines for ovarian cancer. Vaccines 2020;8. doi:10.3390/vaccines8040657. [Epub ahead of print: 05 Nov 2020].

207 Zhang X, He T, Li Y, et al. Dendritic cell vaccines in ovarian cancer. Front Immunol 2020;11:613773.

208 Belderbos RA, Aerts JGJV, Vroman H. Enhancing dendritic cell therapy in solid tumors with immunomodulating conventional treatment. Mol Ther Oncolytics 2019;13:67-81.

209 Overwijk WW, Theoret MR, Finkelstein SE, et al. Tumor regression and autoimmunity after reversal of a functionally tolerant state of self-reactive CD8+ T cells. J Exp Med 2003;198:569-80.

210 Westergaard MCW, Andersen R, Chong C, et al. Tumour-reactive T cell subsets in the microenvironment of ovarian cancer. $\mathrm{Br} J$ Cancer 2019;120:424-34.

211 Pedersen M, Westergaard MCW, Milne K, et al. Adoptive cell therapy with tumor-infiltrating lymphocytes in patients with metastatic ovarian cancer: a pilot study. Oncoimmunology 2018;7:e1502905

212 Zhang AW, McPherson A, Milne K, et al. Interfaces of malignant and immunologic clonal dynamics in ovarian cancer. Cell 2018;173:1755-69.

213 Wagner DL, Fritsche E, Pulsipher MA, et al. Immunogenicity of CAR T cells in cancer therapy. Nat Rev Clin Oncol 2021;18:379-93.

214 Liu G, Rui W, Zhao X, et al. Enhancing CAR-T cell efficacy in solid tumors by targeting the tumor microenvironment. Cell Mol Immunol 2021;18:1085-95.

215 Kershaw MH, Westwood JA, Parker LL, et al. A phase I study on adoptive immunotherapy using gene-modified T cells for ovarian cancer. Clin Cancer Res 2006;12:6106-15.

216 Fucà G, Reppel L, Landoni E, et al. Enhancing chimeric antigen receptor T-cell efficacy in solid tumors. Clin Cancer Res 2020;26:2444-51.

217 Rafiq S, Hackett CS, Brentjens RJ. Engineering strategies to overcome the current roadblocks in car T cell therapy. Nat Rev Clin Oncol 2020;17:147-67.

218 Fang J, Ding N, Guo X, et al. Î̃PD-1-mesoCAR-T cells partially inhibit the growth of advanced/refractory ovarian cancer in a patien along with daily apatinib. J Immunother Cancer 2021;9:e001162.

219 Kaufman HL, Maciorowski D. Advancing oncolytic virus therapy by understanding the biology. Nat Rev Clin Oncol 2021;18:197-8.

220 Andtbacka RHI, Collichio F, Harrington KJ, et al. Final analyses of OPTiM: a randomized phase III trial of talimogene laherparepvec versus granulocyte-macrophage colony-stimulating factor in unresectable stage III-IV melanoma. J Immunother Cancer 2019;7:145

221 Santos JM, Heiniö C, Cervera-Carrascon V, et al. Oncolytic adenovirus shapes the ovarian tumor microenvironment for potent tumor-infiltrating lymphocyte tumor reactivity. J Immunother Cancer 2020;8:e000188.

222 Chesney J, Puzanov I, Collichio F, et al. Randomized, open-label phase II study evaluating the efficacy and safety of Talimogene Laherparepvec in combination with ipilimumab versus ipilimumab alone in patients with advanced, unresectable melanoma. J Clin Oncol 2018;36:1658-67.

223 Petroni G, Galluzzi L. Impact of treatment schedule on the efficacy of cytostatic and immunostimulatory agents. Oncoimmunology 2021;10:1889101.

224 Wang L, Zhang F, Cui J-Y, et al. CAFs enhance paclitaxel resistance by inducing EMT through the IL-6/JAK2/STAT3 pathway. Oncol Rep 2018;39:2081-90. 